\title{
Regulated Dynamic Trafficking of Neurexins Inside and Outside of Synaptic Terminals
}

\author{
Christian Neupert, ${ }^{1 \star}$ Romy Schneider, ${ }^{2 \star}$ Oliver Klatt, ${ }^{1,2}$ Carsten Reissner, ${ }^{1}$ Daniele Repetto, ${ }^{1}$ Barbara Biermann, ${ }^{1,2}$ \\ - Katharina Niesmann, ${ }^{1}$ Markus Missler, ${ }^{1,3}$ and Martin Heine ${ }^{2,4}$ \\ ${ }^{1}$ Institute of Anatomy and Molecular Neurobiology, Westfälische Wilhelms-University, 48149 Münster, Germany, ${ }^{2}$ Molecular Physiology Group, Leibniz- \\ Institute of Neurobiology, 39118 Magdeburg, Germany, ${ }^{3}$ Cluster of Excellence EXC 1003, Cells in Motion, 48149 Münster, Germany, and ${ }^{4}$ Center for \\ Behavioral Brain Sciences, 39118 Magdeburg, Germany
}

Synapses depend on trafficking of key membrane proteins by lateral diffusion from surface populations and by exocytosis from intracellular pools. The cell adhesion molecule neurexin (Nrxn) plays essential roles in synapses, but the dynamics and regulation of its trafficking are unknown. Here, we performed single-particle tracking and live imaging of transfected, epitope-tagged Nrxn variants in cultured rat and mouse wild-type or knock-out neurons. We observed that structurally larger $\alpha$ Nrxn molecules are more mobile in the plasma membrane than smaller $\beta$ Nrxns because $\alpha$ Nrxns displayed higher diffusion coefficients in extrasynaptic regions and excitatory or inhibitory terminals. We found that well characterized interactions with extracellular binding partners regulate the surface mobility of Nrxns. Binding to neurexophilin-1 (Nxph1) reduced the surface diffusion of $\alpha$ Nrxns when both molecules were coexpressed. Conversely, impeding other interactions by insertion of splice sequence \#4 or removal of extracellular $\mathrm{Ca}^{2+}$ augmented the mobility of $\alpha \mathrm{Nrxns}$ and $\beta$ Nrxns. We also determined that fast axonal transport delivers Nrxns to the neuronal surface because Nrxns comigrate as cargo on synaptic vesicle protein transport vesicles (STVs). Unlike surface mobility, intracellular transport of $\beta \mathrm{Nrxn}^{+}$STVs was faster than that of $\alpha$ Nrxns, but both depended on the microtubule motor protein KIF1A and neuronal activity regulated the velocity. Large spontaneous fusion of $\mathrm{Nrxn}^{+}$STVs occurred simultaneously with synaptophysin on axonal membranes mostly outside of active presynaptic terminals. Surface Nrxns enriched at synaptic terminals where $\alpha$ Nrxns and Nxph $1 / \alpha$ Nrxns recruited GABA $\mathrm{R}_{\mathrm{A}}$ subunits. Therefore, our results identify regulated dynamic trafficking as an important property of Nrxns that corroborates their function at synapses.

Key words: autism; GABA(A) receptors; imaging; neuroligin; quantum dots; synapse function

Significance Statement

Synapses mediate most functions in our brains and depend on the precise and timely delivery of key molecules throughout life. Neurexins (Nrxns) are essential synaptic cell adhesion molecules that are involved in synaptic transmission and differentiation of synaptic contacts. In addition, Nrxns have been linked to neuropsychiatric diseases such as autism. Because little is known about the dynamic aspects of trafficking of neurexins to synapses, we investigated this important question using single-molecule tracking and time-lapse imaging. We identify distinct differences between major Nrxn variants both in surface mobility and during intracellular transport. Because their dynamic behavior is highly regulated, for example, by different binding activities, these processes have immediate consequences for the function of Nrxns at synapses.

\section{Introduction}

Synapse differentiation and plasticity are fast and highly regulated processes that require the coordinated targeting of a pleth-

Received Sept. 30, 2014; revised Aug. 26, 2015; accepted Aug. 26, 2015.

Author contributions: C.N., M.M., and M.H. designed research; C.N., R.S., O.K., C.R., D.R., B.B., and M.H. performed research; C.R. and K.N. contributed unpublished reagents/analytic tools; C.N., R.S., O.K., C.R., D.R., B.B., M.M., and M.H. analyzed data; M.M. and M.H. wrote the paper.

This work was supported by Deutsche Forschungsgemeinschaft (Grant SFB629-TPB11 to M.M. and Grant HE3604/2-1 to M.H.), and Land Sachsen-Anhalt (LSA Research Group Molecular Physiology Grant to M.H.). We thank K. Kerkhoff, S. Opitz, A. Lenuweit, H. Wickborn, and I. Wolff for excellent technical assistance; M. Klose for biochem- ora of specialized molecules to presynaptic and postsynaptic compartments (McAllister, 2007; Chia et al., 2013). Presynaptic proteins can be delivered from intracellular pools via synaptic vesicle protein transport vesicles (STVs), piccolo-bassoon transport vesicles (PTVs), or dense-core vesicles (DCVs; Ahmari et al., 2000; Zhai et al., 2001; Sabo et al., 2006; de Wit et al., 2009a; Bury and Sabo, 2011; Park et al., 2011; van de Bospoort et al., 2012). In

\footnotetext{
ical experiments during early stages of the project; and J. Klingauf (Biophysics, Münster) and members of our laboratories for discussion.

The authors declare no competing financial interests.

${ }^{*}$ C.N. and R.S. contributed equally to this work.
} 
addition, synaptic membrane proteins can be distributed by lateral diffusion of surface populations (Ribrault et al., 2011; Chang et al., 2012; Cijsouw et al., 2014; Schneider et al., 2015). Because neurotransmission differs between synapses even of the same neuron (Rozov et al., 2001; Ermolyuk et al., 2012), regulated trafficking of synaptic components contributes to their functional specification (Lau and Zukin, 2007; Vithlani et al., 2011; Anggono and Huganir, 2012; Dolphin, 2012; Chia et al., 2013). The molecular determinants controlling the shaping of synapses with different properties are incompletely understood, but it was hypothesized that the transmembrane proteins neurexins (Nrxns) in concert with binding partners play a role (Shen and Scheiffele, 2010; Missler et al., 2012; Reissner et al., 2013). Little is known about the trafficking of Nrxn to synapses except the requirement of the C-terminal PDZ-recognition motif to traverse the secretory pathway (Fairless et al., 2008; Gokce and Südhof, 2013).

Several findings render Nrxns as candidates for the organization of synaptic function. Nrxns represent a polymorphic family of differentially distributed, alternatively spliced molecules (Ullrich et al., 1995; Schreiner et al., 2014; Treutlein et al., 2014), for which an increasing number of binding partners provide extracellular cues (Ichtchenko et al., 1995; Missler et al., 1998; Sugita et al., 2001; Boucard et al., 2005; Ko et al., 2009; de Wit et al., 2009b; Uemura et al., 2010; Matsuda and Yuzaki, 2011; Boucard et al., 2012; Reissner et al., 2014). Both $\alpha$-neurexin ( $\alpha$ Nrxn), with its large extracellular domain, and the shorter $\beta$-neurexin ( $\beta \mathrm{Nrxn}$ ) are able to differentiate synapses in vitro (Dean et al., 2003; Graf et al., 2004; Nam and Chen, 2005). $\alpha$ Nrxns are functionally essential for synaptic transmission at excitatory and inhibitory terminals in many brain areas (Missler et al., 2003; Kattenstroth et al., 2004; Zhang et al., 2005; Etherton et al., 2009; Zhang et al., 2010; Bottos et al., 2011; Aoto et al., 2013). $\beta$ Nrxn have less impact on neurotransmission (Born et al., 2015), consistent with their lower abundance (Schreiner et al., 2015). Finally, together with binding partners, presynaptic Nrxns affect the function of postsynaptic ion channels (Kattenstroth et al., 2004; Heine et al., 2008a; Zhang et al., 2010; Mondin et al., 2011; Aoto et al., 2013; Budreck et al., 2013; Giannone et al., 2013; Born et al., 2014; Born et al., 2015).

In contrast to the established importance of the dynamic trafficking of ion channels (Heine et al., 2008b; Bannai et al., 2009; Dupuis et al., 2014), cell-adhesion molecules as Nrxn often invoke the idea of engaging in relatively immobile trans-synaptic contacts. However, an earlier study predicted from population measurements of pHluorin-tagged Nrxns that their mobility is pertinent to GABAergic synapse maintenance in parvalbumin interneurons (Fu and Huang, 2010). Because most synapses can undergo rapid plasticity (Dobie and Craig, 2011; Kwon and Sabatini, 2011; Chen et al., 2012), here, we investigated the dynamic trafficking of Nrxns outside and inside of synapses. Because nonperturbing antibodies against endogenous Nrxn variants are not available, we relied on overexpression of epitope-tagged proteins. Previous work demonstrated that peroxidase-tagged $\alpha$ Nrxn partially rescues the release phenotype of knock-out mice (Missler et al., 2003; Zhang et al., 2005), and that fluorochrome-tagged Nrxn shows synaptic targeting independent of endogenous

Correspondence should be addressed to either of the following: Markus Missler, Institute of Anatomy and Molecular Neurobiology, Westfälische Wilhelms-University, Vesaliusweg 2-4, Münster 48149, Germany, E-mail:: Markus.Missler@uni-muenster.de; or Martin Heine, Molecular Physiology Group, Leibniz-Institute of Neurobiology, Brenneckestrasse 6, 39118 Magdeburg, Germany, E-mail: Martin.Heine@ifn-magdeburg.de.

DOI:10.1523/JNEUROSCI.4041-14.2015

Copyright $\odot 2015$ the authors $\quad 0270-6474 / 15 / 3513630-19 \$ 15.00 / 0$ protein (Fairless et al., 2008; Gokce and Südhof, 2013). Using single-particle tracking (SPT) and time-lapse imaging of epitope-tagged $\alpha \operatorname{Nrxn}$ and $\beta$ Nrxn variants, we now reveal their distinct and highly regulated dynamic behavior at the surface and intracellularly.

\section{Materials and Methods}

Animals. Rat and mouse pups of either sex were used for primary hippocampal culture and derived from timed-pregnant dams at embryonic day 18 (E18; rats) or E17 (mice). Generation and genotyping of $\alpha$ Nrxndeficient mice has been described previously (Missler et al., 2003). All experiments were performed in accordance with local institutional and government regulations for animal welfare at the Leibniz Institute of Neurobiology (Magdeburg, Germany) under license 53.23-42500 and at University of Münster approved by the Landesamt für Natur, Umwelt und Verbraucherschutz, North Rhine-Westphalia under license 84-02.05.20.11.209.

Antibodies. Primary antibodies were as follows: monoclonal mouse antibody against the lumenal domain of synaptotagmin1, CypHer5Elabeled (SynapticSystems; catalog \#105311CpH), polyclonal rabbit Oyster 550-labeled antibody against the luminal domain of synaptotagmin 1 (SynapticSystems; catalog \#105103C3), polyclonal rabbit oyster 550labeled antibody against the luminal domain of VGAT (SynapticSystems; catalog \#131103C3), polyconal guinea pig against VGluT1 (SynapticSystems; catalog \#135304), polyclonal rabbit antibody (serum) against GFP (Life Technologies; catalog \#A-6455), monoclonal mouse antibody against GFP (Roche; catalog \#11814460001), GFP-Booster Atto 488 (ChromoTek; catalog \#gba488), polyclonal guinea pig antibody against bassoon (SynapticSystems; catalog \#141004), polyclonal rabbit antibody against KIF1A (Sigma-Aldrich; catalog \#SAB2104191), polyclonal rabbit antibody against NEEP21 (Santa Cruz Biotechnology; catalog \#sc135089), polyclonal rabbit antibody against Rab3a (Sigma-Aldrich; catalog \#R2776), polyclonal rabbit antibody against Rab5a (Sigma-Aldrich; catalog \#R4654), monoclonal mouse antibody against Rab7b (SigmaAldrich; catalog \#WH0338382M1), monoclonal mouse antibody against Rab11 (Abcam; catalog \#AB78337), monoclonal mouse antibody against Tubulin (SynapticSystems; catalog \#302211), monoclonal mouse antibody against CASK (Millipore; catalog \#MAB5230), polyclonal rabbit antibodies against $\operatorname{Rim} 1 \alpha$ and Mint1 (gift from T.C. Südhof, Stanford University), and quantum dot 655 anti-mouse (QD-655; Life Technologies; catalog \#Q11022MP). Secondary antibodies were as follows: Alexa Fluor488 goat-anti-rabbit, Alexa Fluor488 goat-anti-mouse IgG (Invitrogen), Cy3-conjugated goat-anti-rabbit, and Cy3-conjugated goat-antimouse IgG (Jackson Immuno Research).

Neuronal cultures. Primary neurons were prepared in HBSS from hippocampi of E17 mice or E18 rats as described previously (Kaech and Banker, 2006). Briefly, cell suspensions obtained after $0.25 \%$ trypsin treatment and trituration were plated onto $18 \mathrm{~mm}$ glass coverslips (Menzel-Glaeser) coated with poly-L-lysine (Sigma-Aldrich) at a density of 20,000 cells per coverslip. After $1-2 \mathrm{~h}$ at $37^{\circ} \mathrm{C}, 5$ coverslips were transferred into a $35 \mathrm{~mm}$ dish containing a $70-80 \%$ confluent monolayer of astrocytes in neurobasal medium supplemented with B27 and $5 \mathrm{~mm}$ glutamine. Cultures were maintained at $37^{\circ} \mathrm{C}$ in a humidified incubator with an atmosphere of $95 \%$ air and $5 \% \mathrm{CO}_{2}$. Neurons were transfected at 4-6 days in vitro (DIV) using calcium phosphate, effectene (Qiagen), or lipofectamine (Life Technologies) and experiments were performed between DIV7 and DIV10 (intracellular transport) or DIV14 and DIV21 (surface mobility, pHluorin). For live imaging experiments, dissociated neurons were seeded onto poly-L-lysin-coated dishes (ibidi) at low density $\left(50-100\right.$ cells $\left./ \mathrm{mm}^{2}\right)$ and cultured with a layer of astrocytes on a coverslip.

Expression vectors and reagents. pSyn5-Nrxn vectors were cloned from earlier variants (Fairless et al., 2008) by replacing CMV with a human synapsin promoter to obtain pSyn5-NENA (EGFP fused at the $\mathrm{N}$ terminus of $\operatorname{Nrxn} 1 \alpha$ ) and pSyn5-NENB (for $\operatorname{Nrxn} 1 \beta$ ). mCherry from pCDNA3.1/hChR2-mCherry replaced EGFP in pSyn5-EchNA and pSyn5-EchNB using oligonucleotide primers MM08-60 (forward, 5' CGA CGA GCT AGC AAG CTT ATG GTG AGC AAG GGC GAG GAG 
G-3') and MM08-30 (reverse, 5' -CGA CGA GCT AGC CTT GTA CAG CTC GTC CAT GCC-3'). For pH-sensitive vectors, a super ecliptic pHluorin was amplified from synapto-pHluorin (provided by Jürgen Klingauf, Münster University, Germany) and inserted in pSyn5-NpHNA and pSyn5-NpHNB (SEP_Nrxn $1 \alpha$ and SEP_Nrxn $1 \beta$ with SEP at N terminus). Oligonucleotide primers MM09-107 (forward, 5'-CGA CGA GCT AGC GGA GCA GGA ATG AGT AAA GGA GAA GAA CTT TTC ACT GG-3') and MM09-108 (reverse, 5'-CGA CGA GCT AGC TCC TGC TCC ACC GGT TTT GTA TAG TTC ATC CAT GCC ATG-3') yielded pHluorin with overhangs containing NheI sites $\left(5^{\prime}\right.$ and $\left.3^{\prime}\right)$, and an AgeI site $\left(3^{\prime}\right)$ to test orientation. For pSyn-Nxph1Cterm-pH [neurexophilin-1 ((Nxph1) with SEP at C terminus], the SEP sequence was amplified using primers MM10-61 (forward, 5'-CGA CGA CCC GGG AGT AAA GGA GAA GAA CTT TTC ACT GGA GTT GTC CCA ATT CTT GTT GAA TTA GAT GGT GAT GTT AAT GG-3') and MM10-62 (reverse, 5' -CGA CGA CCC GGG TCA TTT GTA TAG TTC ATC CAT GCC ATG TGT AAT CCC AGC AGC-3'), yielding pHluorin with XmaI sites. Synaptophysin with pHTomato and HA tags in pSyn5 were generated from pQUAS-Synaptophysin-pHTomato-sv40 (provided by J.Klingauf) via NotI-XbaI sites. For $\mathrm{Ca}^{2+}$ imaging, pGP-CMVGCaMP6f (Addgene) was used.

EGFP-KIF1A plasmid (Lee et al., 2003) was kindly provided by JaeRan Lee (Korea Advanced Institute of Science and Technology, Daejeon, South Korea), EGFP-KIF1A-shRNA (Liu et al., 2012) and shRNAresistant myc-KIF1A (Xue et al., 2010) constructs were generously provided by Judy S. Liu (Center for Neuroscience Research, Children's National Medical Center, Washington, DC). All enzymes for restriction site digest, dephosphorylation, ligation, and appropriate buffers were purchased from New England Biolabs. Primers were generated by SigmaAldrich and PCRs performed with the Expand Long Template PCR kit (Roche Applied Science). DNA fragments were isolated using a standard phenol-chloroform extraction protocol or from agarose gels with a QiaEx kit (Qiagen). All resulting intermediaries and final constructs were confirmed by DNA sequencing.

Time-lapse imaging. To monitor intracellular transport, cultures were placed in HEPES buffer containing the following (in mM): $145 \mathrm{NaCl}, 2.5 \mathrm{KCl}$, $2 \mathrm{CaCl}_{2}, 2 \mathrm{MgCl}_{2}, 10$ Glucose, 10 HEPES, pH 7.4. Cultures were then observed with a spinning disc Axio Observer-Z1 (Visitron) with a dual CCDcamera Orca-D2 (Hamamatsu Photonics) and an EMCCD camera (ImagEM 512 CCD; Hamamatsu) using a 40× Plan-Neofluar oilimmersion objective and heated stage $\left(36^{\circ} \mathrm{C}\right)$. Time-lapse recordings for up to $10 \mathrm{~min}$ with intervals of $100-500 \mathrm{~ms}$ were acquired to analyze vesicle trafficking. Vesicles that never moved were excluded. Trajectories and velocities of moving vesicles were determined via kymograph function in MetaMorph (Molecular Devices). A period was considered mobile when it displayed movement faster than $0 \pm 0.10 \mu \mathrm{m} / \mathrm{s}$. Axons and dendrites were distinguished based on their morphological characteristics. Disruption of cytoskeletal elements was achieved by $5 \mu \mathrm{m}$ latrunculin-A and $10 \mu \mathrm{M} \mathrm{no-}$ codazole (both from Sigma-Aldrich). Neuronal activity experiments were performed with $1 \mu \mathrm{M}$ TTX (Alomone Labs) and depolarizing HEPES buffer containing the following (in mM): $61.5 \mathrm{NaCl}, 60 \mathrm{KCl}, 2 \mathrm{CaCl}_{2}, 2 \mathrm{MgCl}_{2}, 30$ Glucose, and 25 HEPES, pH 7.4. Electrical field stimulation of neuronal cultures transfected with GCamp6f was applied with parallel platinum electrodes and an isolated pulse generator 2100 (AM Systems) in combination with a stimulus isolator (A385; World Precision Instruments) delivering 52 $\mathrm{mA}$ pulses of $1 \mathrm{~ms}$ duration. The stimulus used was $1-16$ trains of $50 \mathrm{APs}$ at $50 \mathrm{~Hz}$ with $5 \mathrm{~s}$ interval.

Immunocytochemistry. Neurons were fixed in 4\% PFA/PBS for 10 min at room temperature, permeabilized in $0.3 \%$ Triton X-100, and blocked in $2 \%$ BSA $/ 25 \mathrm{~mm}$ glycine or $5 \%$ normal goat serum/PBS. Primary and secondary antibodies were diluted in blocking buffer and F-actin was visualized by incubating with Alexa Fluor 488- or Alexa Fluor 568phalloidin (1:100; Invitrogen). Images were taken with epifluorescent microscopes (Zeiss; Imager A2 or Axio Imager.Z2) equipped with a $63 \times$ 1.4 numerical aperture (NA) Plan-Apochromat objectives and CCD cameras (CoolSnap EZ, Roper-Scientific, or Spot Xplorer and apotome Visitron).

Fluorescent recovery after photo bleach. For fluorescent recovery after photo bleach (FRAP), primary neurons transfected with pHluorin- tagged plasmids were perfused with solution containing the following (in $\mathrm{mm}$ ): $145 \mathrm{NaCl}, 2.5 \mathrm{KCl}, 2 \mathrm{MgCl}_{2}, 2 \mathrm{CaCl}_{2}, 10 \mathrm{HEPES}$, and $10 \mathrm{D}$-glucose, $\mathrm{pH}$ 7.4. For low $\mathrm{pH}$, HEPES was replaced by MOPS, pH 5.5. A rapid solution exchange using a theta-glass electrode with low $\mathrm{pH}$-solution in one and extracellular solution containing the following (in $\mathrm{mm}$ ): 50 $\mathrm{NH}_{4} \mathrm{Cl} 95 \mathrm{NaCl}, 2.5 \mathrm{KCl}, 2 \mathrm{MgCl}_{2}, 2 \mathrm{CaCl}_{2}, 10 \mathrm{HEPES}$, and $10 \mathrm{D}$-glucose, $\mathrm{pH}$ 7.4, was used in the other channel-determined fluorescent ratios. Fluorescence was excited using a mercury lamp (DG4; Sutter Instruments) controlled by MetaMorph software (Universal Imaging). To photobleach locally, a diode laser $473 \mathrm{~nm} / 80 \mathrm{~mW}$ (Rapp OptoElectronic) was used at $50-100 \%$ power with a spot illumination time of $10-20 \mathrm{~ms}$. The laser was coupled to the microscope via a galvometric mirror guided by a UGA 40 control unit (Rapp OptoElectronic), which allowed us to photobleach several regions within a short time window $(<200 \mathrm{~ms})$. FRAP was monitored at $10 \mathrm{~Hz}$ and recovery curves were corrected for background noise.

Single-particle tracking. EGFP or pHluorin-tagged proteins were labeled either with QD-655 bound to monoclonal anti-GFP and antiFlag antibodies (Roche; catalog \#11814460001) or nanobodies against GFP (Muyldermans, 2013) conjugated to ATTO 647N (Chromotek; catalog \#gba647N). QD-655 and goat $\mathrm{F}\left(\mathrm{ab}^{\prime}\right) 2$ anti-mouse IgG conjugate $(\mathrm{H}+\mathrm{L})$ highly cross-adsorbed $(0.1 \mu \mathrm{M}$; Life Technologies; catalog \#Q$11021 \mathrm{MP})$ were precoated with mouse anti-GFP $(0.5 \mu \mathrm{g})$ in $10 \mu \mathrm{l}$ of PBS for $30 \mathrm{~min}$ and blocked with casein for $15 \mathrm{~min}$. Transfected neurons were incubated with $0.1-0.01 \mathrm{nM}$ QDs for $1-5 \mathrm{~min}$ at $37^{\circ} \mathrm{C}$, washed in HEPESbuffered physiological solution containing the following (in $\mathrm{mM}$ ): 145 $\mathrm{NaCl}, 2.5 \mathrm{KCl}, 2 \mathrm{MgCl}_{2}, 2 \mathrm{CaCl}_{2}, 10$ HEPES, and 10 D-glucose, $\mathrm{pH} 7.4$, plus $0.5 \% \mathrm{BSA}$, transferred to an open chamber, and imaged. In case of nanobody labeling, cultures were mounted in a Ludin chamber (Life Imaging Services) and anti-GFP nanobodies were applied to the media in a dilution of 1:50,000. The high dilution ensured separation of individual molecules and the reduction of background fluorescence from unbound nanobodies. To visualize active synapses (Kraszewski et al., 1995; Martens et al., 2008), the uptake of fluorophore-coupled antibodies against the luminal domain of synaptotagmin 1 (1:200, precoupled to CypHer5E, SynSys) or VGAT (1:200, Oyster550, SynSys) was used before QD or nanobody labeling. Recordings of anti-GFP QDs labeled GFP-Nrxn relative to synaptotagmin1 or VGAT clusters were conducted with an AxioObserver microscope (Zeiss) equipped with an EMCCD camera (Evolve; Roper Photometrics) using a $100 \times 1.3 \mathrm{NA}$ objective or at a spinning disc Axio Observer-Z1 (Visitron) equipped with an EMCCD camera (ImagEM C9100-13; Hamamatsu) using a $100 \times 1.46$ NA PlanApochromat oil-immersion objective (Zeiss). Fluorescence of QDs and presynaptic markers was excited with a xenon lamp using excitation filters HC 435/40, HC 531/40, and ET 640/30 (Semrock/Chroma) or with a $561 \mathrm{~nm}$ Laser (100 mW; Visitron). Emitted fluorescence was acquired through filters HC 593/40, HC 655/15, and ET Bandpass 690/50, respectively. Recordings of QDs were obtained with an integration time of 30 ms for up to 1000-2000 consecutive frames. QD-labeled Nrxns were followed on randomly selected dendritic regions for up to $20 \mathrm{~min}$. QD fixed to the coverslip allowed to compensate for mechanical drifts of the stage. Nanobody-labeled Nrxns were imaged with an inverted fluorescent microscope (Olympus IX71) with TIRF illumination, a highmagnification objective (100× NA 1.49), and EMCCD camera (iXON Ultra; Andore ). The laser illumination $(630 \mathrm{~nm}, 100 \mathrm{~mW})$ was adjusted to have oblique illumination using $10-20 \%$ of the laser power. The acquisition rate was $50 \mathrm{~Hz}$ with a localization accuracy similar to QD-based SPT $(<50 \mathrm{~nm})$. All recordings of molecular mobility were performed at $36-37^{\circ} \mathrm{C}$.

Tracking analysis. Single QDs were tracked using custom-made software (Groc et al., 2007). Trajectories of single QDs were reconstructed with a point accuracy of 50-60 nm and subtrajectories reconnected when the displacement between 2 frames was 1-2 pixels (maximal dark period of 25 frames). For motion parameters of single molecules, mean squared displacement (MSD) curves were calculated and plotted over time for reconnected trajectories of at least 100 frames (resolution limit for diffusion was $0.001 \mu \mathrm{m}^{2} / \mathrm{s}$ ). Diffusion coefficients were calculated by linear fit of the first four points of the MSD plots versus time (Saxton, 1995). The diffusion coefficient, confinement index, and dwell time were 
A
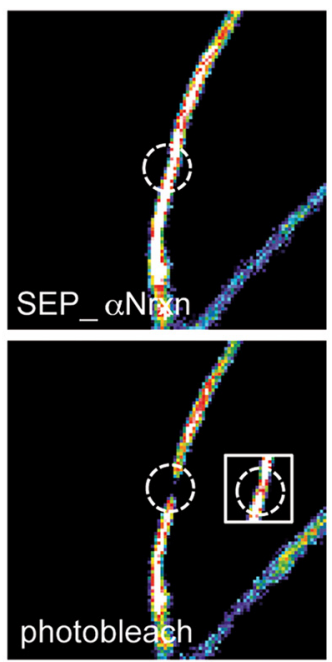

C

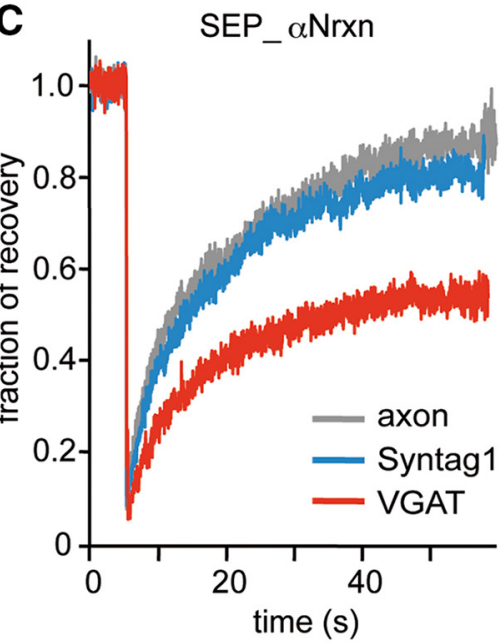

F

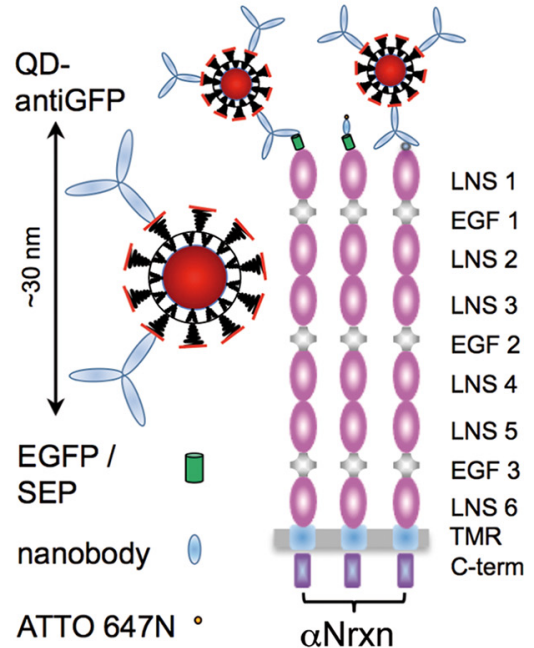

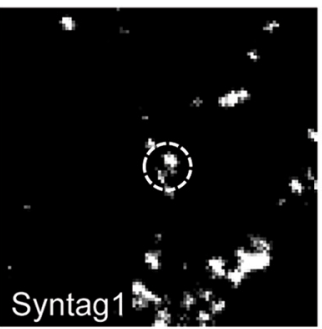

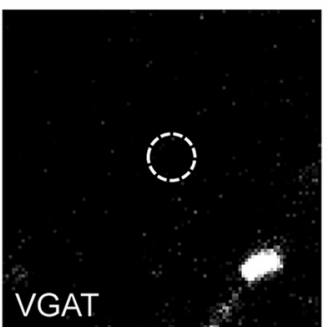

D

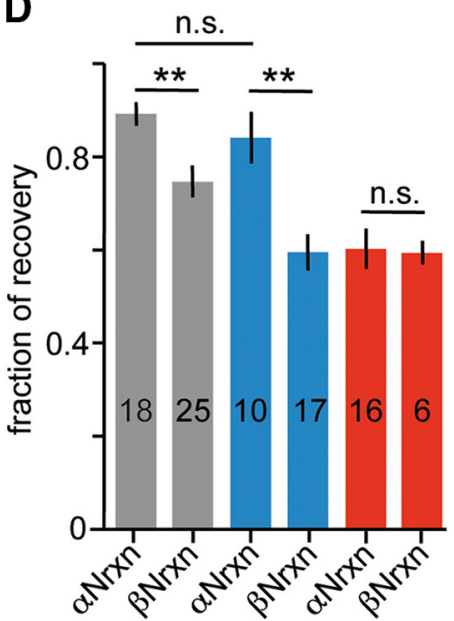

G

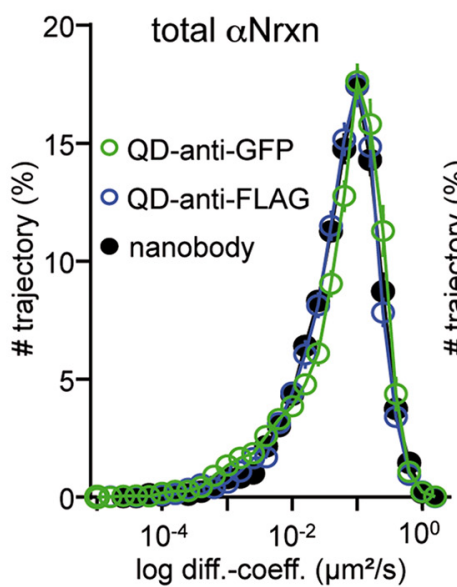

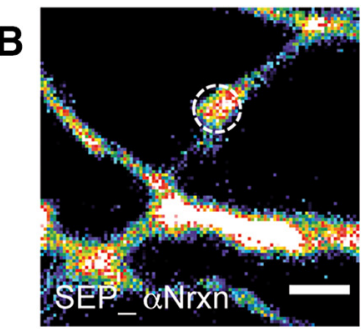
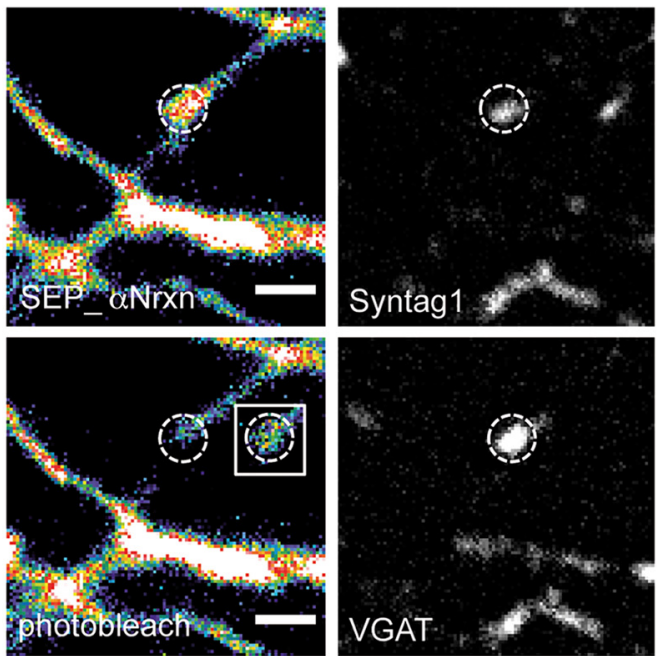

E

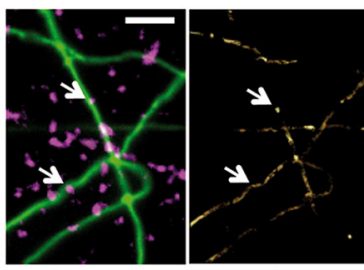

GFP aNrxn with QDot

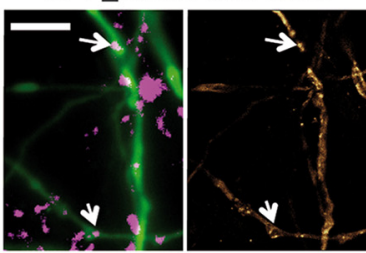

GFP_aNrxn with nanobody

H

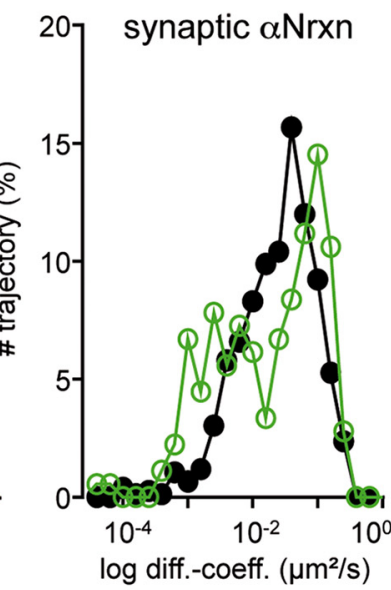

Figure 1. FRAP measurements and single-particle tracking reveal mobile epitope-tagged Nrxn molecules at the cell surface of primary rat hippocampal neurons. $\boldsymbol{A}$, Example of pHluorin(SEP)Nrxn1 $\alpha$ FRAP (circles indicate FRAP region, boxes show recovery after $60 \mathrm{~s}$ ). This sample shows a putatively excitatory synapse identified by anti-synaptotagmin1 (Syntag1), but not anti-VGAT uptake. $\boldsymbol{B}$, Example for Nrxn1 $\alpha$ FRAP at a Syntag $1^{-}$and VGAT ${ }^{+}$putatively inhibitory terminal. Scale bars, $3 \mu \mathrm{m}$. $\boldsymbol{C}$, Recovery curves of $\alpha$ Nrxn fluorescence corrected for steady-state photobleach

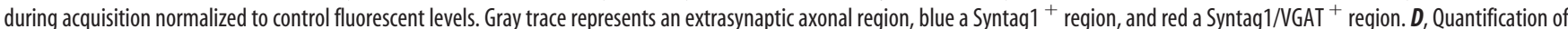
FRAP after 60 s for transfected SEP_Nrxn1 $\alpha$ and SEP_Nrxn1 $\beta$ at axons (gray bars) and at excitatory (blue) or inhibitory (red) synapses. Data are means \pm SEM collected from $6-25$ synapses/FRAP regions from 3- 6 cells of 3 independent cultures. Differences were tested by a one-way ANOVA followed by Newman-Keuls test. ${ }^{* *} p<0.01$. $\boldsymbol{E}$, Sample images of axonal segments transfected with GFP_ $\alpha$ Nrxn (green) and synapses identified by Syntag1-uptake (magenta). Arrows indicate synaptic contacts. Analysis of the localization of QD- (top) or nanobody-ATTO647N (bottom)-labeled $\alpha$ Nrxns reveals only a slight accumulation of molecules in synapses. Scale bars, $5 \boldsymbol{\mu m}$. $\boldsymbol{F}$ - $\boldsymbol{H}$, Single-particle tracking of exogenous $\alpha$ Nrxns performed with QD or nanobodies after transfection of neurons with EGFP/SEP- or Flag-tagged Nrxn1 $\alpha$. Sizes in the legend of the diagram (left) are approximately to scale. $\boldsymbol{F}$, Logarithmic distribution of the surface diffusion coefficient of total $\alpha$ Nrxn ( $\boldsymbol{G}$ ) and of synaptically localized $\alpha \operatorname{Nrxn}(\boldsymbol{H})$ tracked by QD-coupled antibodies against GFP or Flag epitopes and by nanobodies against GFP. Data were collected from 6 cells of 3 independent cultures. 


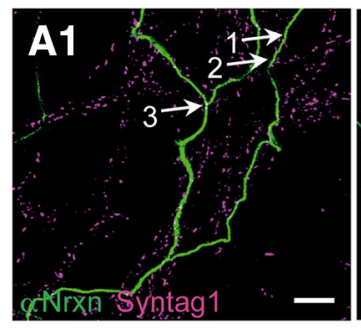

C1

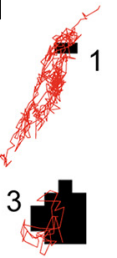

E

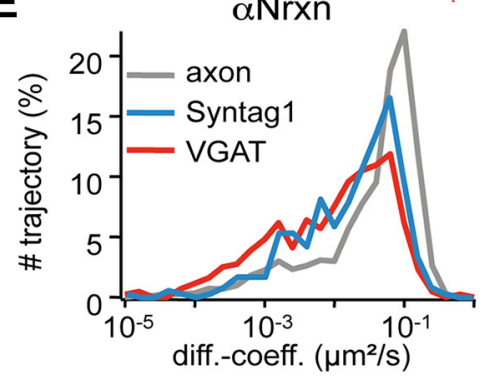

H

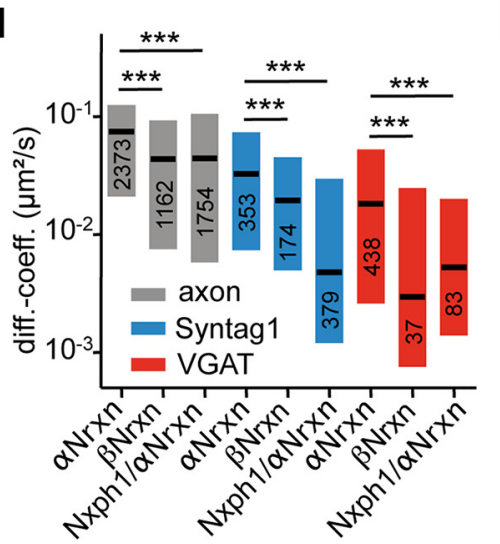

K

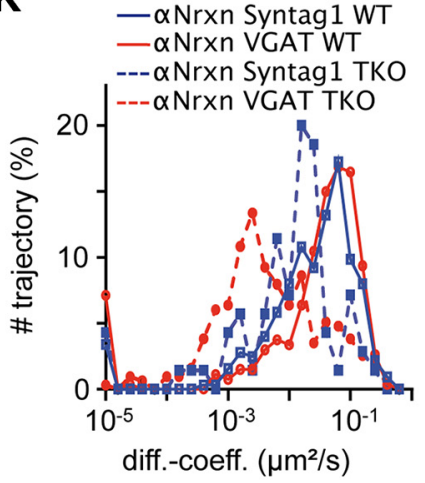

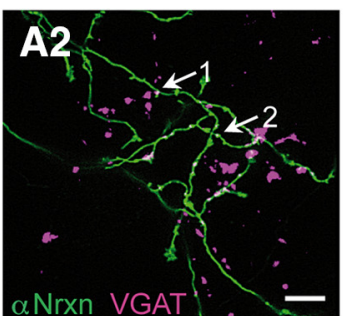

C2

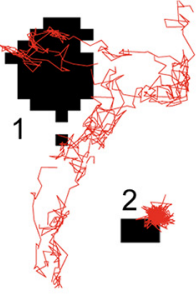

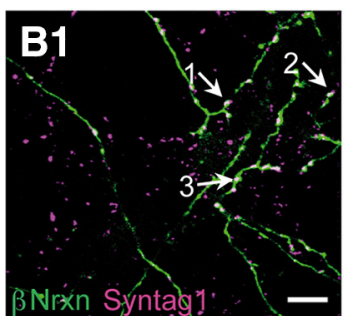

D1

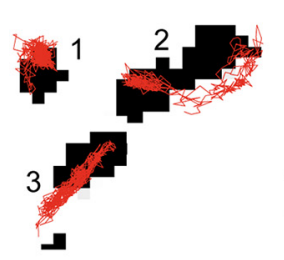

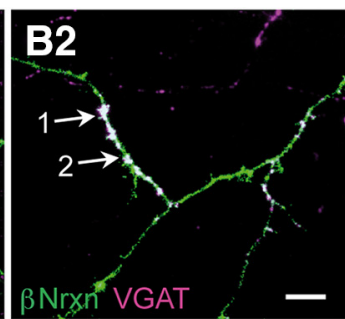

D2

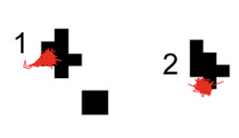

F

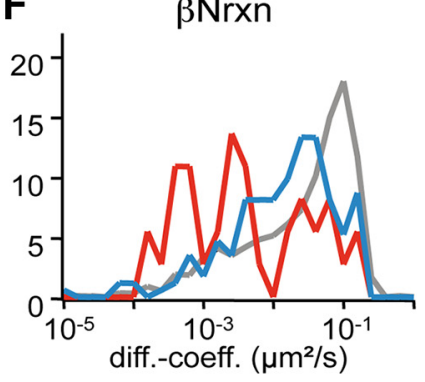

I

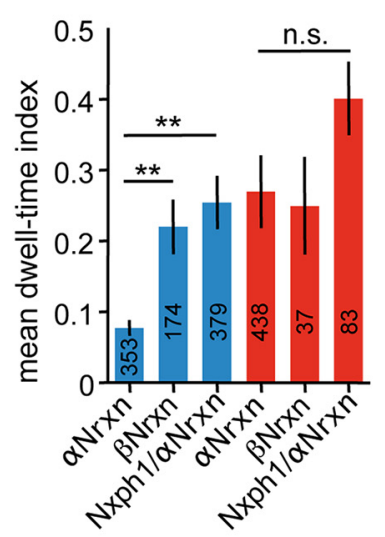

G Nxph $1 / \alpha \mathrm{Nrxn}$

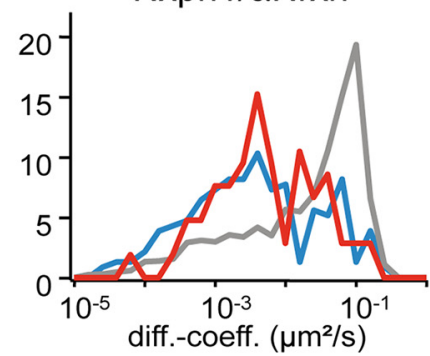

J

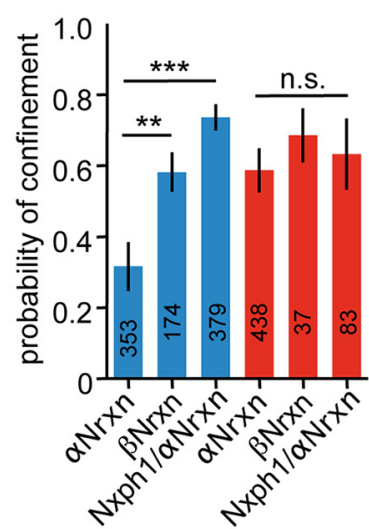

M

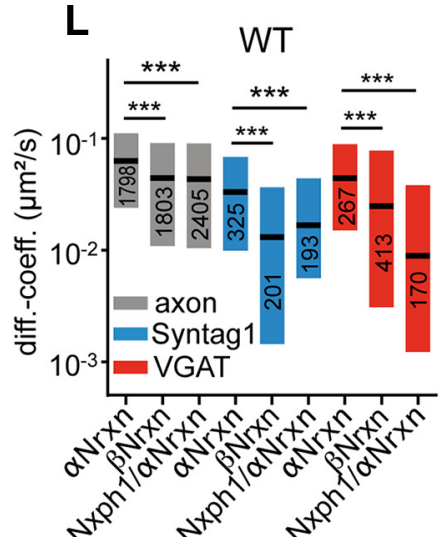

Figure 2. $\alpha$ Nrxns and $\beta$ Nrxns diffuse with distinct surface mobilities extrasynaptically and within excitatory or inhibitory synapses. $\boldsymbol{A}, \boldsymbol{B}$, Colabeling of Nrxn1 $\alpha(\boldsymbol{A})$ or Nrxn $1 \beta(\boldsymbol{B})$ surface populations on transfected rat hippocampal neurons with anti-Syntag1 and anti-VGAT to identify glutamatergic and GABAergic axons and synapses. Scale bars, $10 \mu \mathrm{m}$. $\boldsymbol{C}, \boldsymbol{D}$, Sample trajectories of QD-tracked single $\alpha \operatorname{Nrxn}(\boldsymbol{C})$ and $\beta \operatorname{Nrxn}(\boldsymbol{D})$ molecules at positions indicated by arrows in $(\boldsymbol{A}, \boldsymbol{B})$. Logarithmic distribution of diffusion coefficients for $\alpha$ Nrxn $(\boldsymbol{E})$, $\beta$ Nrxn $(\boldsymbol{F})$, and cotransfected Nxph1/ $\alpha$ Nrxn complex (G) on axons outside synapses (black), inside excitatory (blue), and inside inhibitory (red) synapses. $\boldsymbol{H}$, Median and IQR (25-75\%) of diffusion coefficients with total numbers of analyzed trajectories indicated in bars. Statistical significance was tested by Kruskal-Wallis test followed by a Dunn's test. $\boldsymbol{I}, \boldsymbol{J}$, Dwell-time index $(\boldsymbol{I})$ and probability of confinement $(\boldsymbol{J})$ of $\alpha$ Nrxns, $\beta$ Nrxns, and the Nxph1/ $\alpha$ Nrxn complex reveal higher affinity of $\alpha$ Nrxns and Nxph1/ $\alpha$ Nrxn to inhibitory terminals (red) compared with excitatory presynapses (Figure legend continues.) 
calculated using custom software (Sergé et al., 2002). For QDs in transit between synapses, the dwell-time index was calculated as follows: time spent in synapses/(total acquisition time $\times$ number of exits). For molecules that did not leave a cluster, the dwell-time index was set to 1 . Tracking of single molecules and diffusion analysis for nanobody-labeled Nrxns was done with analysis software running as plug-in for MetaMorph. Localization of single molecules used a wavelet-based identification, followed by a Gaussian fit of its fluorescence in the $x$ and $y$ directions. The detailed workflow and algorithms were described recently (Kechkar et al., 2013). The diffusion coefficients were analyzed similar to the QD-labeled probes using the first four points of the MSD based on trajectories longer than eight points.

Statistical analysis. Data presented are means \pm SEM or represent median and interquartile range (25-75\%), as indicated. Statistical significance was tested with a two-tailed unpaired Student's $t$ test or one-way ANOVA variance test using Prism version 6.0 software (GraphPad Software). Results were denoted statistically significant at $p<0.05$; number $(n)$ of samples/repeats, and exact $p$ values and significance levels are indicated in the Results and in the figure legends.

\section{Results}

\section{Surface mobilities of fluorescently tagged $\alpha$ Nrxns and $\boldsymbol{\beta} \mathrm{Nrxns}$ are distinct and specific}

To visualize Nrxn at the cell surface, we transfected rat hippocampal neurons with pHluorin-tagged $\operatorname{Nrxn} 1 \alpha$ (SEP_ $\alpha$ Nrxn) and $\operatorname{Nrxn} 1 \beta$ (SEP_ $\beta$ Nrxn). We first performed FRAP in combination with labeling of active synapses using spontaneous uptake of antibodies against the luminal domains of synaptotagmin (Syntag1; Fig. 1A) and vesicular GABA transporter (VGAT; Fig. 1B; Kraszewski et al., 1995; Martens et al., 2008). This distinguished between extrasynaptic axonal sites (Syntag1 ${ }^{-}$and $\mathrm{VGAT}^{-}$) and excitatory $\left(\right.$Syntag $\left.{ }^{+}\right)$and inhibitory (VGAT ${ }^{+}$ and Syntag $1^{+}$) terminals. We observed that $\alpha \mathrm{Nrxn}$ fluorescence recovered fully at glutamatergic, but not at GABAergic contacts, whereas $\beta$ Nrxn recovered only partially in both types (Fig. $1 C, D$ ). These results indicate that surface mobilities of $\alpha$ Nrxns and $\beta$ Nrxns are distinct, with higher average dynamics for $\alpha \mathrm{Nrxn}$ (Fig. 1D). However, population measurements such as FRAP are limited by averaging heterogeneous molecule mobility within the area of photobleach $(>1 \mu \mathrm{m})$. We therefore used SPT to resolve the heterogeneity (Triller and Choquet, 2008) and to investigate mobility of Nrxn molecules inside small synapses. To monitor individual pHluorin- or GFP-tagged molecules on the surface of cultured neurons, we first performed proof-ofprinciple experiments showing that this method is suitable for Nrxn (Fig. $1 E-H$ ). We transfected and overexpressed Nrxn1 $\alpha$ fused to tags of different sizes (EGFP and Flag) and tested larger QD-coupled antibodies or smaller nanobodies (Fig. 1E,F). The diagram in Figure $1 F$ shows an approximate comparison of the sizes for different labels used. These recordings resulted in virtually identical diffusion coefficients on axons $\left(\mathrm{D} \approx 0.07 \mu \mathrm{m}^{2} / \mathrm{s}\right.$; Fig. $1 G$ ). Within synaptic terminals, nanobodies demonstrated a more homogeneous distribution of $\operatorname{Nrxn} 1 \alpha$ diffusion, whereas QD tracking also revealed an additional, more immobile popu-

\section{$\leftarrow$}

(Figure legend continued.) (blue). Numbers in bars $(\boldsymbol{H}-\boldsymbol{J})$ represent analyzed $\mathrm{Nrxn}^{+}$synapses from 3-10 rat neuronal cultures and $4-27$ cells. Data in $/$ and $J$ are expressed as means \pm SEM and statistical significance was assessed by one-way ANOVA variance followed by Newman-Keuls test. ${ }^{* *} p<0.001,{ }^{* * *} p<0.0001$. $\boldsymbol{K}-\boldsymbol{M}$, Comparison of surface mobility in hippocampal neurons from WT mice and TKOs lacking endogenous $\alpha$ Nrxns. Diffusion coefficients for $\alpha$ Nrxns in excitatory (blue) and inhibitory (red) terminals of WT (solid line) and TKO (dashed) neurons $(\boldsymbol{K})$. Surface mobility was analyzed in transfected WT $(\boldsymbol{L})$ and TKO $(\boldsymbol{M})$ mouse neurons as in $\boldsymbol{H}$. Numbers in bars $(\boldsymbol{L}, \boldsymbol{M})$ represent the total number of analyzed trajectories from 2-3 mouse hippocampal cultures with 5-17 neurons per genotype. lation (Fig. 1H). Importantly, however, QD and nanobodies both determined the diffusion of mobile Nrxn molecules in synapses at very similar values (Fig. $1 H$ ), indicating that the surface diffusion coefficient of mobile $\alpha \mathrm{Nrxn}$ is amazingly independent of the nature of the tag and tracking system. We therefore opted to use the well characterized QD-coupled anti-GFP antibodies for most SPT experiments because this label allows us, not only to explore diffusion reliably, but also to determine the relative dwell time and confinement area in different membrane compartments (Groc et al., 2007; Heine et al., 2008a; Di Biase et al., 2011; Mondin et al., 2011; Biermann et al., 2014).

\section{Single-molecule mobilities of $\alpha \mathrm{Nrxn}$ and $\beta \mathrm{Nrxn}$ differ on neurites and within synapses}

To evaluate surface mobility in different compartments, we combined QD tracking of $\alpha \mathrm{Nrxn}$ and $\beta \mathrm{Nrxn}$ molecules with live labeling of excitatory and inhibitory synaptic terminals (Fig. $2 A, B$ ), as described above for FRAP (Fig. 1). Trajectories of QD tracks (Fig. 2C,D) or distribution of diffusion coefficients (Fig. $2 E, F)$ demonstrated that most Nrxn molecules, in particular $\alpha$ Nrxn, belong to a very mobile population (D $>10^{-3} \mu \mathrm{m}^{2} / \mathrm{s}$ ) that is only transiently confined at synapses. We found that, at extrasynaptic sites on axons, $\alpha$ Nrxn molecules are more mobile than $\beta$ Nrxn molecules (Fig. $2 H$ ). Diffusion coefficients showed that $\alpha$ Nrxn molecules are almost twice as mobile [ $\alpha$ Nrxn: median $0.071 \mu \mathrm{m}^{2} / \mathrm{s}$, interquartile range (IQR) $=0.019 / 0.12, n=$ 2608 trajectories; $\beta$ Nrxn: 0.044, IQR $=0.0075 / 0.093, n=1162$ trajectories], a surprising observation given the much longer extracellular sequences. These experiments further revealed that $\alpha$ Nrxns have higher diffusion rates inside excitatory and inhibitory synapses compared with $\beta$ Nrxns (Fig. $2 H$ ). This difference was reflected by a lower dwell time index and reduced synaptic confinement, at least in excitatory terminals (Fig. $2 I, J$ ). We then compared the mobility of axonal Nrxn with their diffusion on dendrites because the presence of a small postsynaptic population was proposed (Kattenstroth et al., 2004; Taniguchi et al., 2007). On dendrites, $\alpha$ Nrxns showed also higher mobility than $\beta \mathrm{Nrxns}$, but with a $>10$-fold difference, even though much fewer trajectories were visible on dendrites in general ( $\alpha \mathrm{Nrxn}$ : median: $0.012, \mathrm{IQR}=0.002 / 0.036, n=483$ trajectories; $\beta \mathrm{Nrxn}$ : 0.0006, $\mathrm{IQR}=0.0002 / 0.0011, n=88$ trajectories). Together, our SPT data reveal that Nrxn have an unexpectedly high surface mobility for a so-called synaptic cell adhesion molecule and that $\alpha$ Nrxns, despite their larger extracellular domain, are more mobile than $\beta$ Nrxns, even inside terminals.

To determine whether the high surface mobility is simply a consequence of overexpressing tagged Nrxn in addition to endogenous Nrxn molecules, we performed SPT experiments in neurons from triple knock-out (TKO) mice that lack all $\alpha \mathrm{Nrxn}$ (Missler et al., 2003). A comparison of the dynamics of $\alpha \mathrm{Nrxn}$ and $\beta \mathrm{Nrxn}$ in neurons from rats (Fig. $2 H$ ) and wild-type (WT) mice (Fig. $2 L$ ) revealed that their surface mobilities were similar, showing the same significantly higher mobility of $\alpha$ Nrxns. These data exclude prominent species-specific differences and confirm the distinct mobilities measured in FRAP experiments of primary neurons from rat (Fig. $1 A-D$ ) and of slice cultures from mice (Fu and Huang, 2010). Interestingly, the frequency distribution of diffusion coefficients for $\alpha$ Nrxns analyzed within synaptic terminals of TKO neurons showed a shift to lower mobilities compared with WT (Fig. $2 K$ ). Because $\beta$ Nrxn mobility was largely unchanged on axons or in excitatory synapses of $\alpha \mathrm{Nrxn}$-deficient TKO neurons, the average diffusion of $\alpha$ Nrxns was even lower than $\beta$ Nrxns at extrasynaptic sites and indistinguishable in excit- 
A
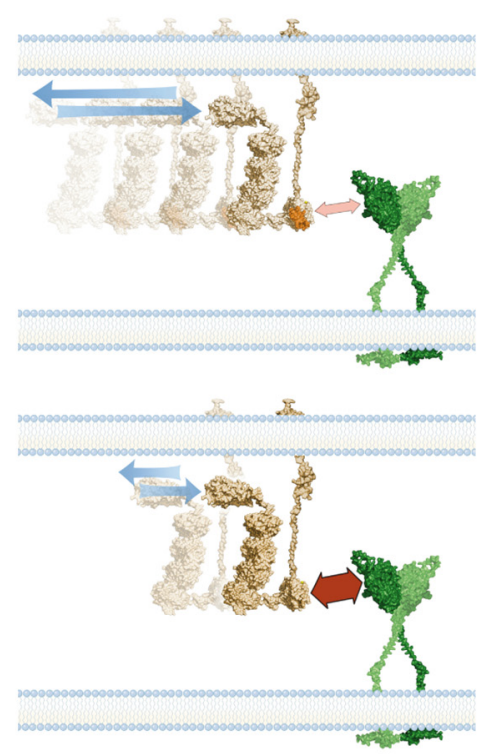

C
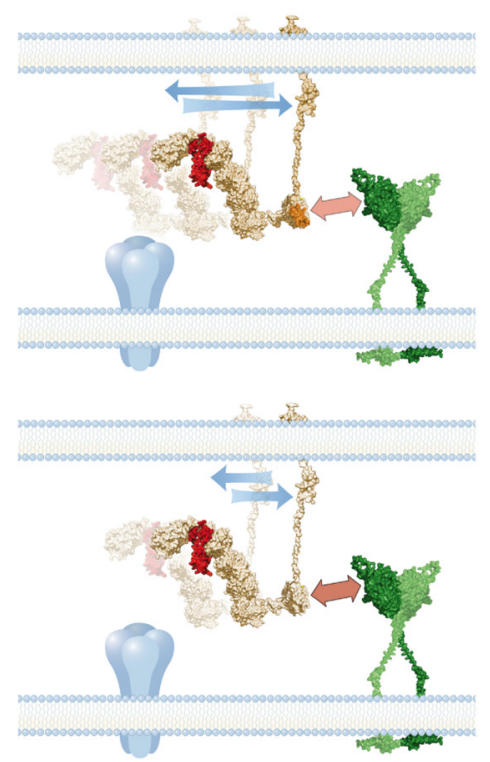

B

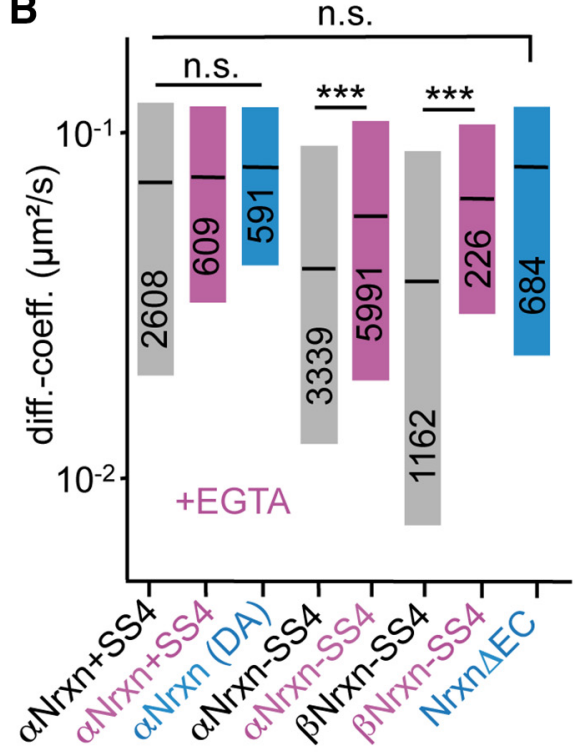

D

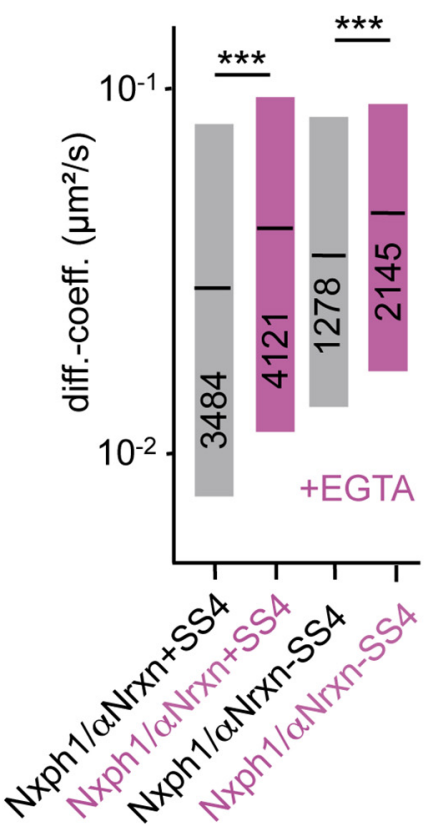

Figure 3. Surface mobility of Nrxns depends on alternative splicing and extracellular $\mathrm{Ca}^{2+}$ concentration. $\boldsymbol{A}, \boldsymbol{B}$, Comparison of mobility between $\operatorname{Nrxn} 1 \alpha$ without insert in SS4 (beige in scheme $\boldsymbol{A},-S S 4$ in $\boldsymbol{B}$ ) and with insert (SS4 orange in scheme $\boldsymbol{A},+S S 4$ in $\boldsymbol{B}$ ) and of $\mathrm{Nrxn} 1 \beta \pm S S 4$, measured by SPT. Extracellular domains are replaced by EGFP to have a reference for maximal diffusion dynamics (Nrxn $\Delta \mathrm{EC}$ ). Chelation of extracellular calcium with $10 \mathrm{~mm}$ EGTA (magenta) is used to assess the general effect of $\mathrm{Ca}^{2+}$-dependent binding activities, for example, with postsynaptic Nlgn (green in schemes). $\mathrm{Ca}^{2+}$ coordination of the LNS6 domain alone is impaired in the point mutation D1183A ( $\alpha$ Nrxn (DA; Reissner et al., 2008). $\boldsymbol{C}, \boldsymbol{D}$, Similar experiment as in $\boldsymbol{A}$ and $\boldsymbol{B}$, but probing the effect of complex formation of $\alpha \mathrm{Nrxn} \pm$ SS4 with cotransfected Nxph1 (red in schemes) on surface mobility. In $\boldsymbol{B}$ and $\boldsymbol{D}$, the median and IQR (25-75\%) of diffusion coefficients with total numbers of analyzed trajectories are indicated in bars. Statistical significance was tested by Kruskal-Wallis test followed by a Dunn's test. ${ }^{* *} p<0.0001$.

atory synapses (Fig. $2 M$ ). In contrast, $\alpha$ Nrxns and $\beta$ Nrxns both displayed lower mobilities inside the inhibitory synapses of $\alpha$ Nrxn TKO (Fig. 2M), thereby maintaining the difference observed in WT (Fig. $2 H, L$ ). These data indicate that overexpression of fluorescently tagged $\alpha$ Nrxns in WT neurons leads to a moderate overestimation of their average surface mobility. Future experiments in $\beta \mathrm{Nrxn} \mathrm{KO}$ mice will have to test whether the absolute mobility of $\beta$ Nrxns was also slightly overestimated in WT neurons, likely reinstating the difference between $\alpha$ Nrxns and $\beta$ Nrxns in front of their respective null backgrounds. More importantly, however, we conclude that removal of endogenous protein did not abolish the mobility of $\alpha$ Nrxns, a remarkable finding for a molecule capable of multiple transsynaptic interactions (Reissner et al., 2013). In addition, the TKO background did not change characteristic differences between $\alpha$ Nrxn mobilities at extrasynaptic sites and inside both types of terminals (Fig. 2M), suggesting that the much lower diffusion in inhibitory terminals is an important property. Finally, the difference between $\alpha$ Nrxns and $\beta$ Nrxns in WT neurons (Fig. $2 \mathrm{H}, L$ ), which disappeared in $\alpha$ Nrxn TKO neurons, is largely due to lower $\alpha$ Nrxn diffusion with unchanged $\beta N r x n$ diffusion (Fig. $2 M$ ). These data argue for a specificity of their respective surface mobilities, supporting our previous hypothesis of mostly nonredundant functions of $\alpha$ Nrxns and $\beta$ Nrxns (Zhang et al., 2005). Together, our results suggest that SPT of tagged Nrxns reliably reflects their distinct dynamics inside and outside of synapses.

\section{Surface mobilities of Nrxns are regulated by extracellular binding activities}

An explanation for the higher mobility of Nrxn $1 \alpha$ compared with Nrxn $1 \beta$, which share identical C-terminal sequences, may consist of specific binding activities of their distinct extracellular domains. To investigate this idea, we first made use of the $\alpha$ Nrxn-specific binding partner Nxph1 (Missler and Südhof, 1998). In contrast to Nrxn, Nxph isoforms are restricted to subpopulations of neurons (Petrenko et al., 1996; Beglopoulos et al., 2005), presenting a test case if local availability of interaction partners alters diffusion dynamics. Strikingly, coexpression of Nxph1 strongly reduced the mobility of $\alpha$ Nrxns within synapses of rat and mouse WT neurons (Fig. 2G, $H, L$ ). The diffusion coefficient of the Nxph $1 / \alpha$ Nrxn complex within excitatory $\left(\mathrm{D}=0.0048 \mu \mathrm{m}^{2} / \mathrm{s}\right)$ and inhibitory $\left(\mathrm{D}=0.0052 \mu \mathrm{m}^{2} / \mathrm{s}\right)$ terminals dropped compared with $\alpha$ Nrxn alone $\left(\mathrm{D}_{\mathrm{exc}}=0.033 \mu \mathrm{m}^{2} / \mathrm{s}, \mathrm{D}_{\mathrm{inh}}=0.018\right.$ $\mu \mathrm{m}^{2} / \mathrm{s}$; Fig. $2 H, L$ ), and this was accompanied by an increase of the dwell time and confinement in glutamatergic but not inhibitory synapses (Fig. $2 I, J$ ). In $\alpha \mathrm{Nrxn}$ TKO neurons, the Nxph $1 / \alpha$ Nrxn complex mobility was not reduced extrasynaptically and at excitatory terminals compared with $\alpha$ Nrxns alone, whereas dynamics were still lower in inhibitory synapses (Fig. 2M). These results could indicate that coexpression of Nxph1 with $\alpha$ Nrxns encounters additional binding partners in GABAergic terminals, leading to reduced mobility independent of the presence of endogenous $\alpha$ Nrxns. This is a 

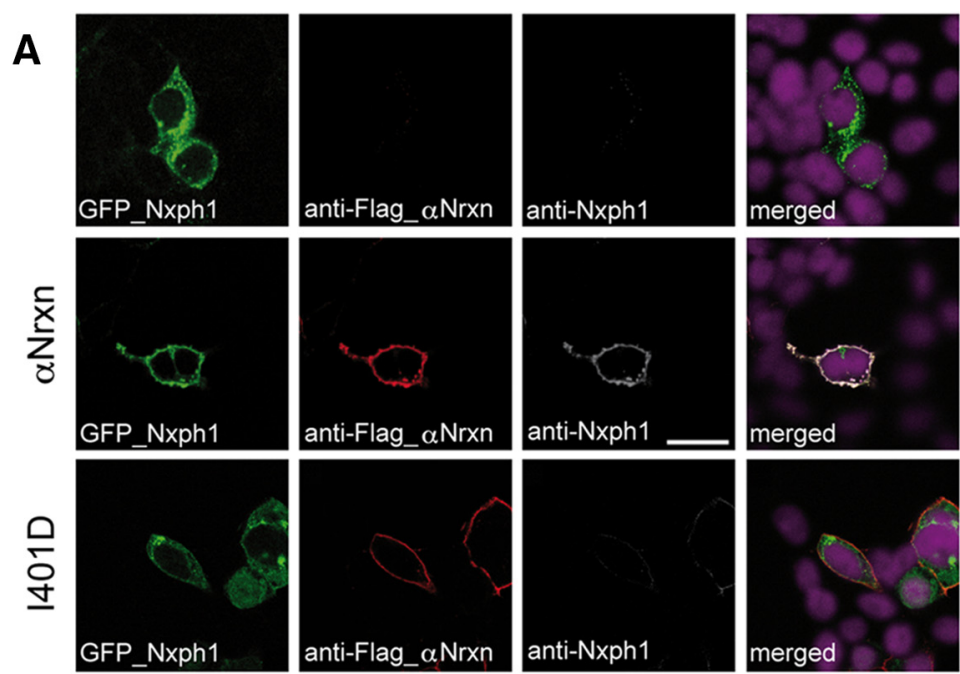

B
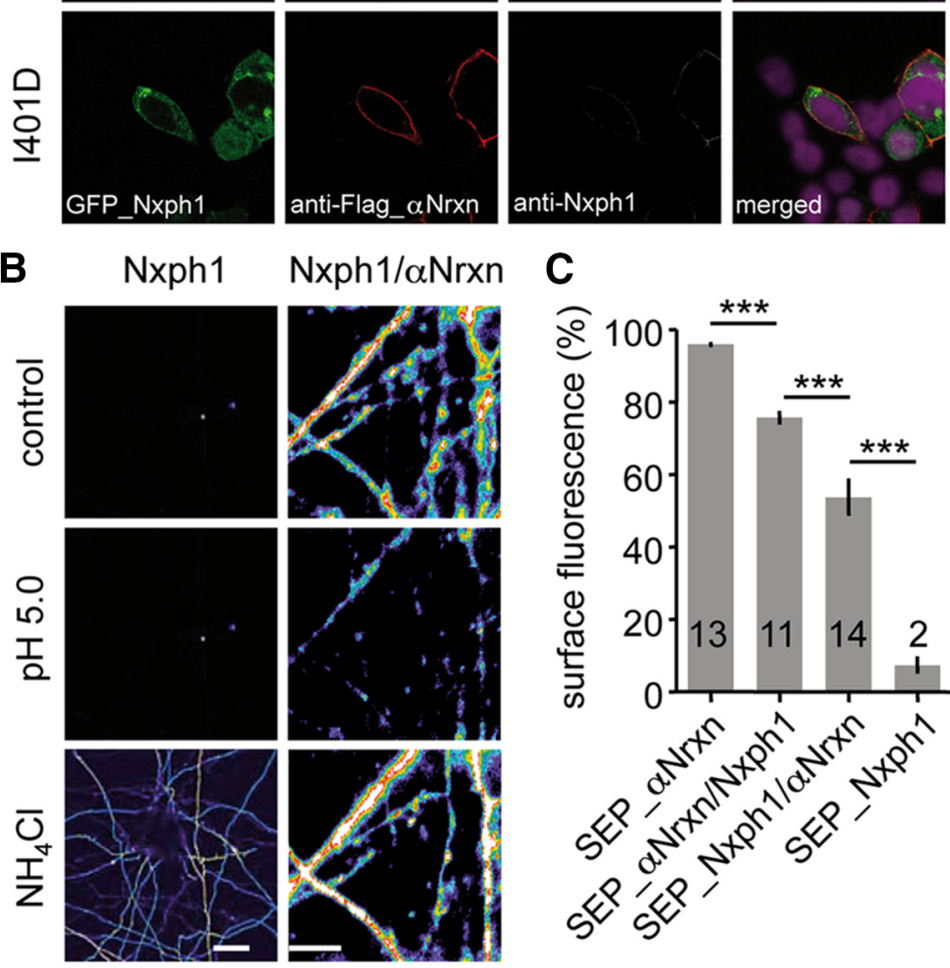

\section{C}

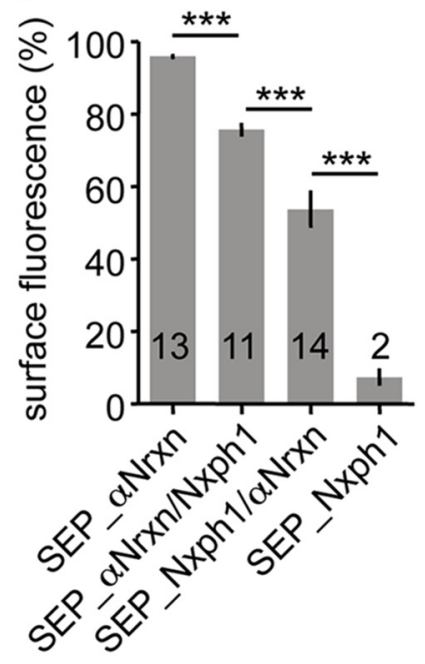

D

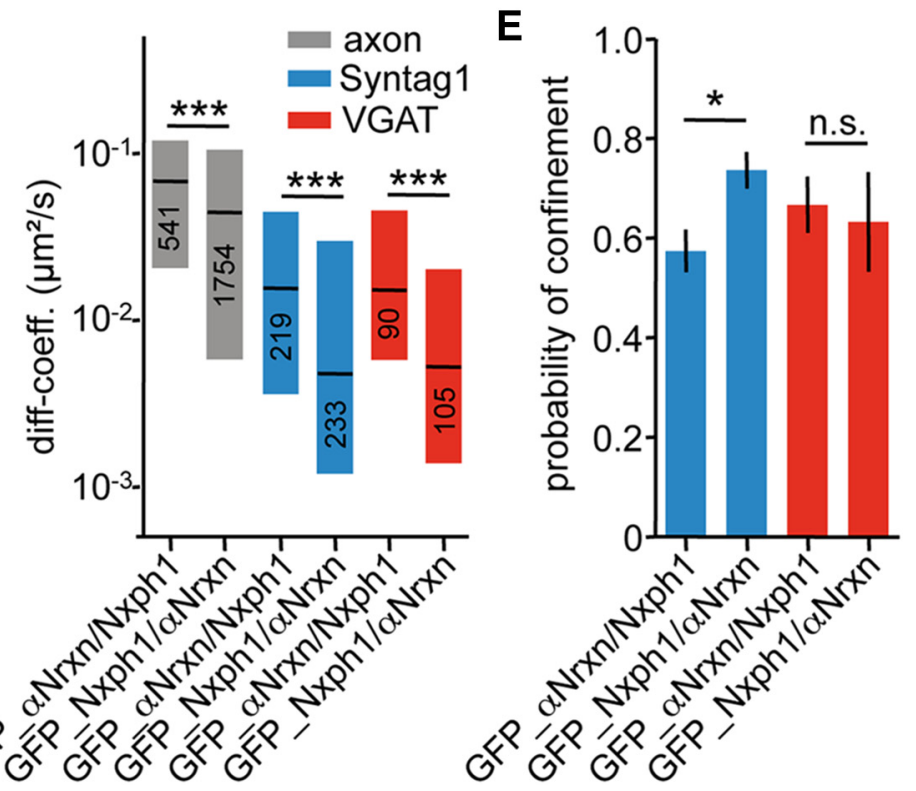

Figure 4. Nxph1 requires coexpression with $\alpha$ Nrxns for targeting but not vice versa. $\boldsymbol{A}$, GFP-tagged Nxph1, when transfected alone, accumulates inside heterologous HEK293 cells and is not detected extracellularly at the cell surface by live labeling with antibodies against Nxph1 (top). Cotransfection of GFP-Nxph1 with a Flag-tagged full-length Nrxn1 $\alpha$ results in a ring-like staining pattern of colocalized Nxph1/ $\alpha$ Nrxn by live labeling with antibodies to the Flag_Nrxn1 $\alpha$ and Nxph1 moieties (middle panels). physiologically attractive hypothesis because we recently showed that genetic deletion or transgenic overexpression of Nxph1 in mice actually modulates inhibitory synaptic function and receptors (Born et al., 2014).

To extend our analysis to the influence of trans-synaptic binding activities and to include $\beta \mathrm{Nrxn}$ in this analysis, we next examined the role of alternative splicing at splice site 4 (SS4) and of $\mathrm{Ca}^{2+}$ sensitivity in Nrxn surface mobility (Fig. 3A). These parameters are crucial because they determine interactions of Nrxn with postsynaptic partners neuroligins, LRRTMs, cerebellin, and dystroglycan (Ichtchenko et al., 1995; Sugita et al., 2001; Boucard et al., 2005; Reissner et al., 2008; Ko et al., 2009; de Wit et al., 2009b; Uemura et al., 2010; Matsuda and Yuzaki, 2011). If the relative immobility of $\beta \mathrm{Nrxn}$ depends on stronger binding to these partners, we should see a higher mobility in the absence of $\mathrm{Ca}^{2+}$ or with splice variants carrying an insert in SS4. Extracellular chelation of $\mathrm{Ca}^{2+}$ by 10 mM EGTA in fact mobilized $\beta$ Nrxns, but did not alter the diffusion of an extracellularly truncated version of Nrxn used as a control (Nrxn $\Delta$ EC; Fairless et al., 2008; Fig. 3B). We also tested the $\mathrm{Ca}^{2+}$-dependent mobility of the splice variants $\alpha \operatorname{Nrxn}(-\mathrm{SS} 4)$ and $\alpha \operatorname{Nrxn}(+\mathrm{SS} 4)$, which differ in their $\mathrm{Ca}^{2+}$-dependent binding affinities to neuroligin-1 because presence of the splice insert impedes the interaction ( $\mathrm{Re}$ issner et al., 2008). In agreement, the mobility of the $\alpha \mathrm{Nrxn}(+\mathrm{SS} 4)$ variant did not show changes to extracellular $\mathrm{Ca}^{2+}$ chelation or mutation of its $\mathrm{Ca}^{2+}$ interaction site $[\alpha \operatorname{Nrxn}(\mathrm{DA}) ;$ Fig. $3 B]$, whereas $\alpha \operatorname{Nrxn}(-$ SS4 $)$ was more mobile at a low

Mutation of a key binding residue in $\alpha$ Nrxn (I401D; Reissner et al., 2014) prevents surface delivery of Nxph1 (bottom). Scale bar, $20 \mu \mathrm{m}$. B, Sample images of pHluorin(SEP)_Nxph1 (left; scale bar, $20 \mu \mathrm{m}$ ) and SEP_Nxph1/ $\alpha$ Nrxn (right; scale bar, 5 $\mu \mathrm{m})$ cotransfected into primary neurons under control buffer conditions at pH 5.0 and after $\mathrm{NH}_{4} \mathrm{Cl}$ treatment to equilibrate intracellular and extracellular pH at 7.4. C, Nxph1 coexpressed with $\alpha$ Nrxns is detected at the cell surface independently of which moiety carries the pHluorin. Quantification of surface fluorescence within axons in (\%) of the total fluorescence is shown. Data are means \pm SEM collected from 2-14 cells of 2-3 hippocampal cultures at DIV 14-21.D, E, Complex formation with Nxph1 decreases the surface mobility of $\alpha$ Nrxns at synapses. Median and IQR (25-75\%) of diffusion coefficients (D) and probability of confinement $(\boldsymbol{E})$ of cotransfected Nxph $1 / \alpha$ Nrxn complexes are shown, in which either $\alpha$ Nrxns or Nxph1 carried the EGFP tag. Total numbers of analyzed trajectories are indicated in bars. Statistical significance in $\boldsymbol{C}-\boldsymbol{E}$ is tested by Kruskal-Wallis test followed by a Dunn's test. ${ }^{*} p<$ $0.05,{ }^{* * *} p<0.0001$. 

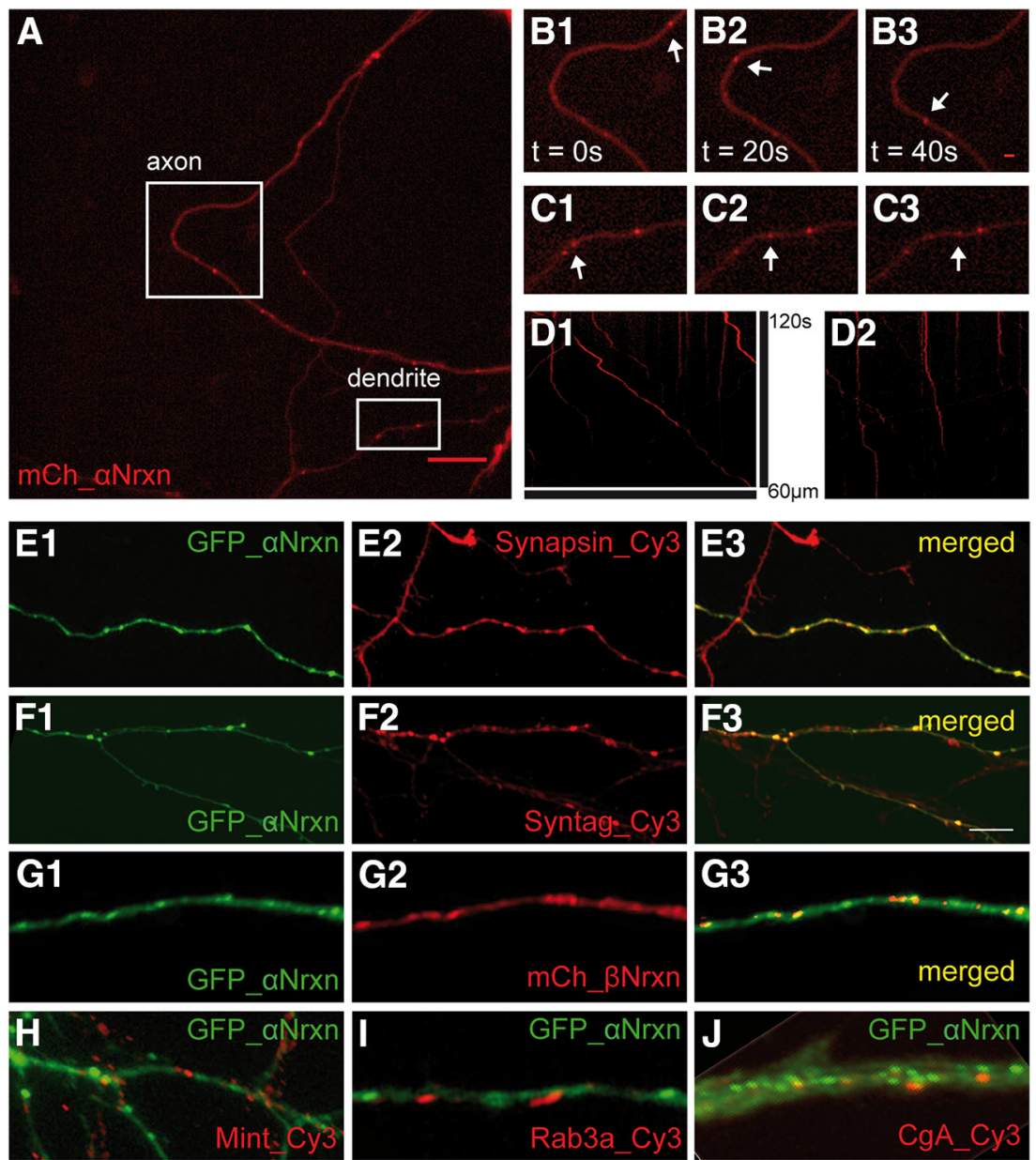

K

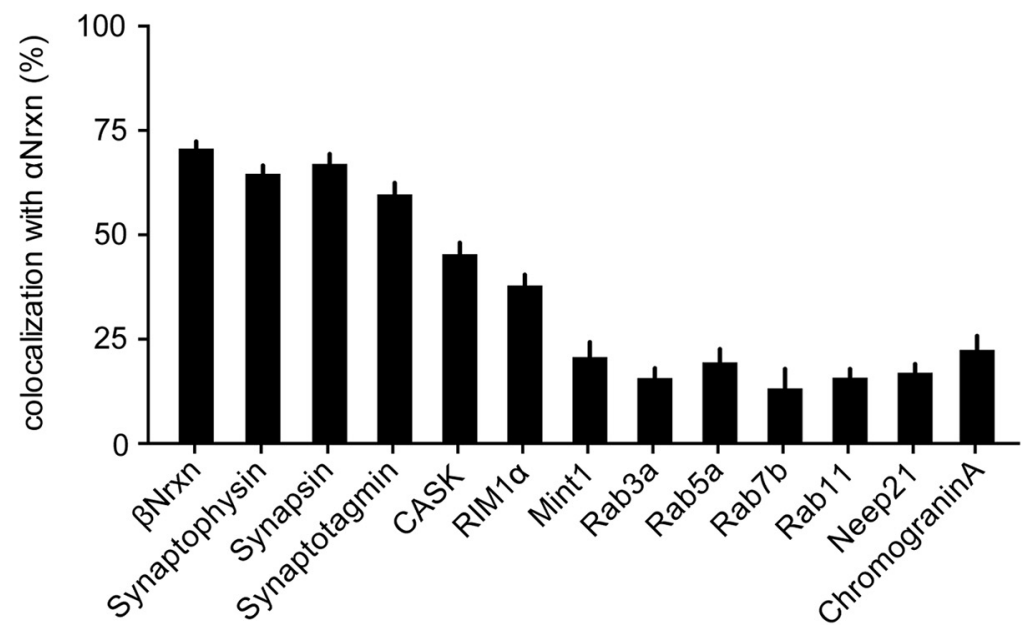

Figure 5. Intracellular Nrxn ${ }^{+}$transport vesicles colocalize with marker molecules of STVs. $\boldsymbol{A}-\boldsymbol{D}$, Examples of Nrxn1 $\alpha^{+}$transport vesicles migrating within axons ( $\boldsymbol{B}$, marked area in $\boldsymbol{A})$ and dendrites $(\boldsymbol{C}$, marked area in $\boldsymbol{A})$ in primary hippocampal neurons. Their velocity was determined from respective kymographs as in $\boldsymbol{D}$. Scale bars: $\boldsymbol{A}, 20 \mu \mathrm{m} ; \boldsymbol{B}, \boldsymbol{C}, 5 \mu \mathrm{m}$. $\boldsymbol{E}-\boldsymbol{J}, \mathrm{GFP} \alpha \alpha \mathrm{Nrxn}^{+}$transport vesicles colocalized strongly with STV marker proteins as synapsin $(\boldsymbol{E})$ and synaptotagmin $1(\boldsymbol{F})$ and also with Nrxn1 $\beta(\boldsymbol{G})$. Double labeling of GFP_ $\alpha \operatorname{Nrxn}$ with $\operatorname{Mint} 1(\boldsymbol{H})$, the synaptic vesicle precursor Rab3a, and chromogranin-A as a DCV component ( $\boldsymbol{(})$ was less apparent. Scale bar in $\boldsymbol{F 3}, 10 \mu \mathrm{m} . \boldsymbol{K}$, Degree of colocalization was expressed as percentage overlap with GFP_ $\alpha$ Nrxn using ImageJ. Data are expressed as means \pm SEM and were derived from a total of 671 neurons/38 transfected cultures.

$\mathrm{Ca}^{2+}$ concentration (Fig. 3B). Importantly, coexpression of Nxph1 with $\alpha \operatorname{Nrxn}(+$ SS4 $)$ or $\alpha \operatorname{Nrxn}(-S S 4)$ strongly increased the $\mathrm{Ca}^{2+}$ sensitivity for both variants (Fig. 3C,D). Although our experiments with $\mathrm{Ca}^{2+}$ chelation or alternative splicing did not allow us to determine directly which postsynaptic partners contribute to the effect, recent biochemical data allow a hypothesis: the enhanced sensitivity of the Nxph $1 / \alpha$ Nrxn complex to $\mathrm{Ca}^{2+}$. dependent binding activities could suggest that the Nxph1 association with the LNS2 domain of $\alpha$ Nrxn blocks the interaction with $\alpha$-dystroglycan at the same LNS2 domain (Reissner et al., 2014). Such a scenario should be particularly prominent for the most abundant splice variant in cortical neurons, $\alpha \mathrm{Nrxn}(+\mathrm{SS} 4)$ (Ullrich et al., 1995; Aoto et al., 2013), which favors association with neuroligins lacking the B insert (Reissner et al., 2014) and consistently showed a large increase in surface mobility when $\mathrm{Ca}^{2+}$ was chelated (Fig. 3D).

\section{Surface targeting and mobility of \\ Nxph1 requires $\alpha$ Nrxn}

The strong effect of Nxph 1 on $\alpha$ Nrxn diffusion raised the question of whether Nxph1 is only active when bound to $\alpha$ Nrxn. Based on our analysis of the binding epitope (Reissner et al., 2014), we hypothesized that correct folding of Nxph1 and formation of the Nxph $1 / \alpha \mathrm{Nrxn}$ complex requires coexpression in the same cell. Here, we addressed this idea directly by transfecting GFP_Nxph1 alone and in combination with Flag_Nrxn1 $\alpha$ into heterologous cells that contain neither molecule endogenously (Fig. 4A). We discovered that efficient targeting of Nxph1 to the surface required coexpression with $\alpha \mathrm{Nrxn}$ and that, in transfections of Nxph1 alone, no surface population could be detected by live incubation with antibodies against Nxph1 (Fig. 4A). Moreover, cotransfection of Nxph 1 with an $\alpha$ Nrxn carrying a single point mutation that strongly reduces binding (I401D; Reissner et al., 2014) showed only very little Nxph1 at the surface (Fig. 4A). These data indicate that normal complex formation with $\alpha \mathrm{Nrxn}$ is necessary and sufficient to deliver Nxph1 to the surface, at least in heterologous cells.

We next validated the strong dependence of Nxph1 on $\alpha$ Nrxns in neurons. The pHluorin-tagged constructs failed to detect significant surface populations of Nxph1 when it was transfected alone (Fig. $4 B, C$ ). Coexpressed Nxph $1 / \alpha$ Nrxn, in contrast, was reliably observed at the neuronal surface independently of which partner carried the pHluorin moiety (Fig. $4 B, C)$. Interestingly, a proportion of the pHluorin_Nxph1/ $\alpha$ Nrxn complex remained intracellularly, as evident from the lower surface expression compared with pHluorin_ $\alpha$ Nrxn alone (Fig. $4 C$ ). Coexpression of a pHluorin_ $\alpha \mathrm{Nrxn} / \mathrm{Nxph} 1$ complex, 

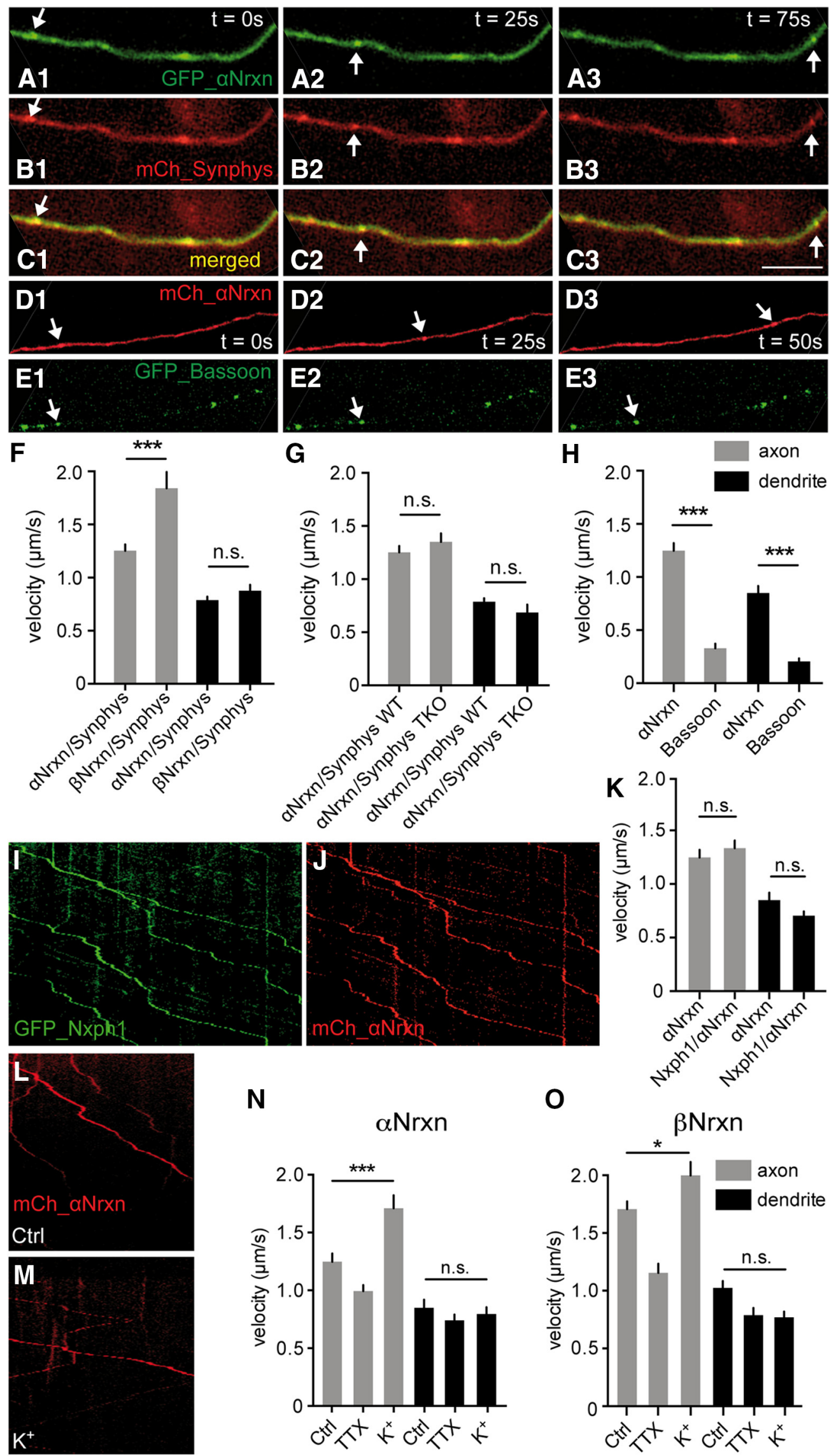

Figure 6. Distinct velocities and regulation of $\alpha \mathrm{Nrxn}$ - and $\beta \mathrm{Nrxn}{ }^{+}$STVs. $\boldsymbol{A}$-C, Example of GFP_Nrxn1 $\alpha$ comigrating with mCherry_synaptophysin at the speed of fast axonal transport in axons of primary hippocampal neurons. $\boldsymbol{D}, \boldsymbol{E}$, No comigration and different speed was observed with cotransfected bassoon as marker protein of PTVs. Scale (Figure legend continues.) 
in which $\alpha$ Nrxn carried the fluorochrome, displayed an intermediate surface fluorescence (Fig. 4C). We therefore hypothesized that not all $\alpha$ Nrxn molecules were complexed to Nxph1, even when coexpressed in the same cell. We tested this idea by comparing the surface mobility of the two coexpression versions of the complex, pHluorin/GFP_Nxph $1 / \alpha$ Nrxn or pHluorin/ GFP_ $\alpha$ Nrxn/Nxph1, using QD-coupled anti-GFP for SPT. We observed that the diffusion coefficient was always lower when Nxph 1 carried the tracked pHluorin/GFP moiety (Fig. 4D). This result indicates that a proportion of uncomplexed $\alpha$ Nrxn molecules reached the surface when pHluorin/GFP_ $\alpha$ Nrxn and Nxph1 were cotransfected. This effect was particularly prominent inside synaptic terminals compared with extrasynaptic sites (Fig. 4D) without increasing confinement strongly (Fig. 4E). Together, these findings indicate that neurons restrict the amount of more immobile Nxph $1 / \alpha$ Nrxn complexes at their surface compared with $\alpha$ Nrxns alone. Such a restriction raises the question, however, of if and how delivery from intracellular pools contributes to the surface population of Nrxn.

\section{STVs transport Nrxn toward synapses}

To analyze how Nrxns and the Nxph $1 / \alpha$ Nrxn complex are targeted to the surface and to synapses, we built on an earlier study in which we revealed that Nrxns require their C-terminal PDZrecognition motif to traverse the secretory pathway via a hitherto uncharacterized class of transport vesicles (Fairless et al., 2008). Although this earlier study relied on immunolabeling of fixed neuronal cultures, we now used live imaging to characterize the dynamic trafficking of Nrxns. We first transfected primary hippocampal neurons separately with GFP- or mCherry-tagged $\alpha$ Nrxns and $\beta$ Nrxns and then studied the migration of their transport vesicles in axonal and dendritic processes (Fig. $5 A-C$ ). We observed that $\mathrm{Nrxn}^{+}$vesicles primarily show a unidirectional, anterograde movement in axons, whereas they moved more bidirectionally in dendrites. This was quantitatively reflected by a tendency, albeit not significant, for more pausing vesicles (axon: $0.013 \pm 0.001$ pauses/s, dendrite: $0.017 \pm 0.003$; $p=0.18$ ), which is consistent with published data (Sabo et al., 2006; Bury and Sabo, 2011). To determine the velocity of mobile $\mathrm{Nrxn}^{+}$transport vesicles, we analyzed their kymographs (Fig. $5 D)$. Strikingly, we found that Nrxns generally move faster within axons $\left(\operatorname{Nrxn}_{\mathrm{ax}}\right)$ than in dendrites $\left(\mathrm{Nrxn}_{\mathrm{de}}\right)$ and that $\alpha \mathrm{Nrxns} \mathrm{mi}-$ grate more slowly than $\beta \mathrm{Nrxns}\left(\alpha \mathrm{Nrxn}_{\mathrm{ax}}: 1.2 \pm 0.071 \mu \mathrm{m} / \mathrm{s}\right.$, $\alpha \mathrm{Nrxn}_{\mathrm{de}}: 0.8 \pm 0.070, p=0.0091 ; \beta \mathrm{Nrxn}_{\mathrm{ax}}: 1.7 \pm 0.067$, $\beta \mathrm{Nrxn}_{\mathrm{de}}: 1.0 \pm 0.062, p=0.0001 ; n=45-47$ cells $/ 4$ transfected cultures per condition). Although the values in axons are within the published range of fast vesicular transport (Vallee and Bloom, 1991) and argue for transport on STVs or DCVs, other pathways such as PTVs or endosomes cannot be excluded based on velocities alone. We therefore performed colabeling experiments with known marker proteins (Fig. 5E-J) and quantified colocalization

(Figure legend continued.) bar, $5 \mu \mathrm{m}$. $\boldsymbol{F}$, Comparison of comigrating $\alpha$ Nrxn/synaptophy$\sin ^{-}$and $\beta$ Nrxn/synaptophysin ${ }^{+}$STVs in axons (gray bars) and dendrites (black bars). $\mathbf{G}$, Comparison of $\alpha \mathrm{Nrxn} /$ synaptophysin mobility in control (WT) and TKO neurons lacking all endogenous $\alpha$ Nrxn. $\boldsymbol{H}, \alpha$ Nrxn ${ }^{+}$STV s migrate faster than bassoon ${ }^{+}$PTVs when cotransfected into the same neurons. $\boldsymbol{I}-\boldsymbol{K}$, Coexpression of Nxph1 with $\alpha$ Nrxn has no effect on the velocity of intracellular traffic in axons and dendrites. $\boldsymbol{L}-\mathbf{0}$, Kymographs and average velocities of $\mathrm{Nrxn}^{+}$ STVs under control conditions and after incubation with TTX or $\mathrm{K}^{+}$to modulate neuronal activity. Data in $\boldsymbol{F}-\boldsymbol{H}, \boldsymbol{K}, \boldsymbol{N}$, and $\boldsymbol{O}$ are expressed as means \pm SEM and were derived from a total of $>220$ neurons/ 24 transfected cultures. Statistical significance was tested by Student's $t$ test. ${ }^{* * *} p<0.001$ by percentage of colabeled vesicles (Fig. $5 K$ ). $\alpha$ Nrxns and $\beta$ Nrxns showed a high degree of colocalization with synaptophysin, synapsin, and synaptotagmin-1 (60-75\%; Fig. 5K), established markers of STVs (Ahmari et al., 2000; Sabo et al., 2006). In addition, proteins directly or indirectly associated with the $\mathrm{C}$ terminus of Nrxn, such as CASK or $\operatorname{Rim} 1 \alpha$, were also frequently colocalized during trafficking (Fig. $5 \mathrm{~K}$ ), confirming earlier data (Fairless et al., 2008). In contrast, markers such as Rab3a for synaptic vesicle precursors, Rab5a for early endosomes, Rab7b for late endosomes/lysosomes, Rab11 or NEEP21 for recycling endosomes, and chromograninA for DCVs revealed only moderate or little colocalization (Fig. $5 K$ ). These data suggest that Nrxns are primarily transported as cargo on STVs, pointing to a major pathway toward synapses.

To prove that Nrxns not only colocalize with relevant markers, but actually comigrate with STVs, we cotransfected GFP-tagged $\alpha$ Nrxn or $\beta$ Nrxn along with mCherry-tagged synaptophysin and observed mostly synchronous movements (Fig. $6 A-C$ ). As a negative control, we repeated the experiment with mCherry_ $\alpha$ Nrxn and GFP_Bassoon, a marker for PTVs that move at slower speed, and found no comigration (Fig. $6 D, E$ ). We then determined the velocity of $\alpha \mathrm{Nrxn} /$ synaptophysin- and $\beta \mathrm{Nrxn} /$ synaptophysin-colabeled STVs from kymographs separately in axons and dendrites. Mobile Nrxn/synaptophysin ${ }^{+}$STVs were present in all processes, in agreement with our data from fixed cultures (Fairless et al., 2008), but they were generally faster in axons compared with dendrites (Fig. $6 F$ ), confirming our initial observation (Fig. 5). Interestingly, $\beta \mathrm{Nrxn}^{+}$ STVs moved with a higher velocity than $\alpha$ Nrxn in axons, whereas no significant difference was found in dendrites (Fig. $6 F$ ). To rule out the possibility that these differences were simply caused by the presence of endogenous protein, of which there is more $\alpha$ Nrxns than $\beta$ Nrxns in brains (Schreiner et al., 2015), we performed the experiment in TKO neurons lacking all $\alpha$ Nrxns (Missler et al., 2003). However, no difference was observed between the velocity of $\alpha \mathrm{Nrxn} /$ synaptophysin $^{+}$STVs in control and TKO neurons (Fig. 6G), suggesting that overexpressed Nrxns reliably reflected their intracellular trafficking. Finally, to evaluate the presence and velocity of different classes of transport vesicles in the same neuron, we cotransfected labeled $\alpha$ Nrxns and bassoon and found higher speed for Nrxn ${ }^{+}$STVs in axons and dendrites compared with bassoon ${ }^{+}$PTVs (Fig. $6 \mathrm{H}$ ), consistent with their nonoverlapping migration (Fig. $6 D, E)$. Similar to surface mobility, these data from intracellular transport reveal distinct dynamics for $\alpha$ Nrxns and $\beta$ Nrxns, but with opposite results; that is, $\beta \mathrm{Nrxn}^{+} \mathrm{STV}$ s migrated faster than $\alpha$ Nrxns, at least in axons.

\section{Determinants of intracellular transport of Nrxns differ from surface diffusion}

To determine whether intracellular transport of Nrxn is regulated by Nxph1 binding, as was shown for surface mobility (Figs. 2, 3, 4), we cotransfected Nxph $1 / \alpha$ Nrxn and determined the velocities from kymographs compared with uncomplexed $\alpha$ Nrxn (Fig. 6I,J). Unlike its effect on surface mobility, complex formation of Nxph $1 / \alpha \mathrm{Nrxn}$ did not change the velocity of STVs in axons or dendrites (Fig. $6 K$ ). To rule out the possibility that coexpression of Nxph 1 acts by altering the preference of $\alpha$ Nrxns for axonal targeting, we compared pHluorin(SEP)_Nxph1 and HA_Nrxn1 $\alpha$ fluorescence intensity normalized to cotransfected soluble RFP (Biermann et al., 2010) and found a similar axon-to-dendrite ratio $[\mathrm{Nxph} 1 / \mathrm{RFP}=$ 2.86, $\operatorname{Nrxn} 1 \alpha / \operatorname{RFP}=2.34, n=7$ cells, nonsignificant (n.s.)] Together, these results suggest that $\alpha \mathrm{Nrxn}^{+}$STVs move with defined velocity independently of the binding of Nxph1. 
Because several studies indicated that neuronal activity modulates the velocity of STV s carrying other synaptic cell adhesion molecules (de Wit et al., 2006; Wittenmayer et al., 2009), we also addressed this aspect. We reduced activity with $1 \mu \mathrm{M}$ TTX or enhanced it with high potassium stimulation $\left(60 \mathrm{~mm} \mathrm{~K}^{+}\right.$for $30 \mathrm{~min}$ before imaging). As was evident from representative kymographs (Fig. $6 L, M$ ), $\alpha \mathrm{Nrxn}^{+}$ and $\beta \mathrm{Nrxn}^{+}$STVs within axons reduced their velocity under TTX, but increased migration with stimulation (Fig. $6 \mathrm{~N}, \mathrm{O}$ ). In contrast, we observed no alterations of the velocity of Nrxn ${ }^{+}$STVs in dendrites under identical conditions (Fig. $6 \mathrm{~N}, \mathrm{O}$ ), suggesting that the axonal, but not dendritic, population of Nrxn ${ }^{+}$STVs is regulated by changes in neuronal activity. Interestingly, the difference in axonal velocity between $\alpha$ Nrxns and $\beta$ Nrxns disappeared under reduced activity and became much less apparent with enhanced activity (Fig. $6 \mathrm{~N}, \mathrm{O}$ ), revealing that Nrxns are cargo on the same type of STVs, as suspected from their colocalization (Fig. $5 G$ ).

Finally, to determine whether intracellular transport of Nrxn depends on the microtubule cytoskeleton and on the motor protein KIF1A, as predicted for STVs (Hirokawa et al., 2009), we performed pharmacological experiments that interrupt different cytoskeletal elements. We treated transfected cultures with $5 \mu \mathrm{M}$ nocodazol to inhibit microtubule polymerization or with $2.5 \mu \mathrm{M}$ latrunculin-A to block F-actin formation (de Wit et al., 2006; Wittenmayer et al., 2009). We observed breakdown of the actin cytoskeleton with fluorochrome-coupled phalloidin and of the microtubule integrity with anti-tubulin antibodies (data not shown). We then compared the effect on Nrxn-STV migration (Fig. 7A,B) and found that Nrxn ${ }^{+}$STVs moved with normal velocity under control conditions and latrunculin-A (e.g., $\alpha$ Nrxn in axons with DMSO: $1.31 \pm 0.08 \mu \mathrm{m} / \mathrm{s}$; with latrunculin-A: $1.36 \pm 0.14, n=53$ neurons $/ 4$ transfections, n.s.). Under nocodazol, however, $\mathrm{Nrxn}^{+}$vesicles remained relatively immobile, showing little movement in axons or dendrites $(\alpha \mathrm{Nrxn}$ in axons with nocodazol: $0.24 \pm 0.02 \mu \mathrm{m} / \mathrm{s}, p<$ $0.001)$. To support these data, we investigated whether KIF1A is the molecular motor involved in transporting $\mathrm{Nrxn}^{+}$ STVs. We determined a high degree of colocalization and comigration of Nrxn with transfected GFP_KIF1A (Fig. 7C-F), but also with endogenous KIF1A visualized by immunolabeling (Fig. 7G). The velocities of $\alpha \mathrm{Nrxn} / \mathrm{KIF} 1 \mathrm{~A}^{+}$and
A

$\alpha$ Nrxn
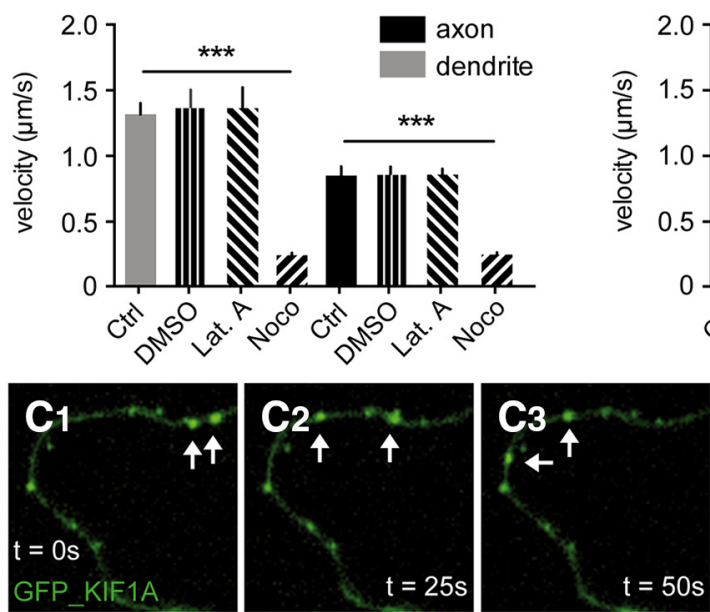

B

$\beta$ Nrxn
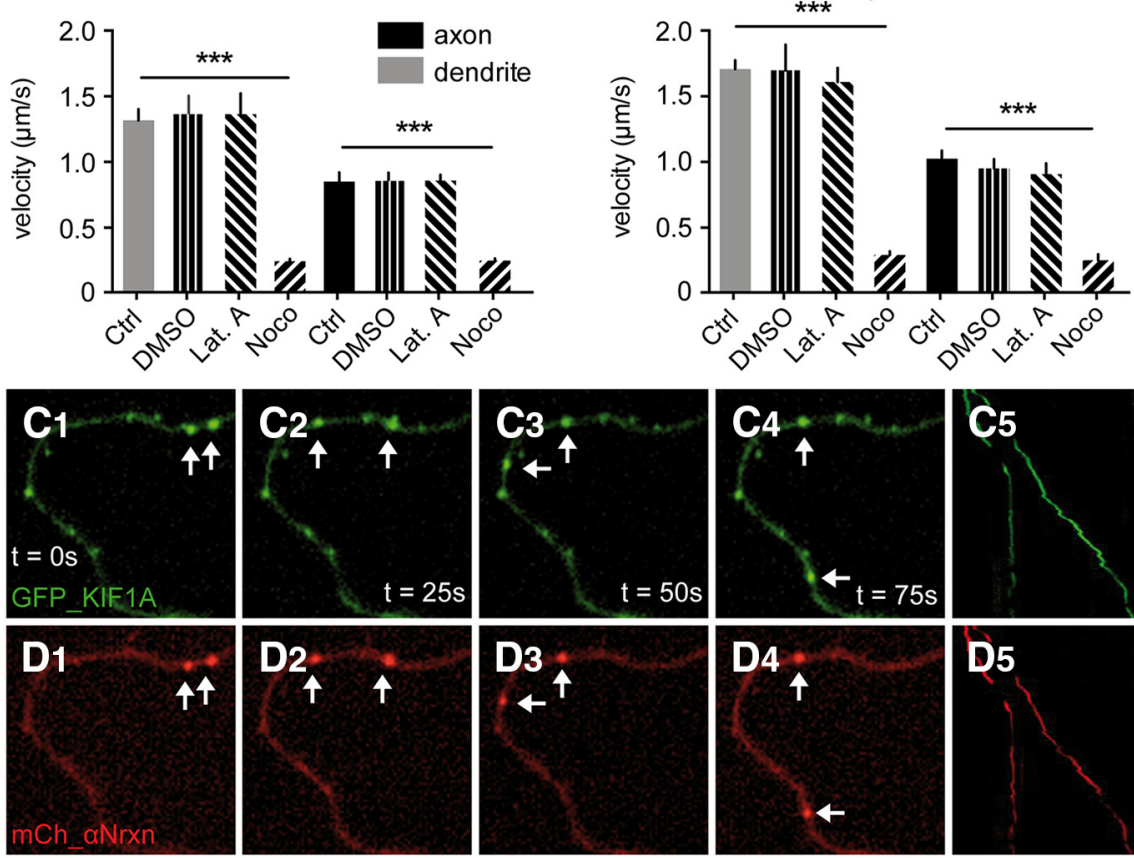

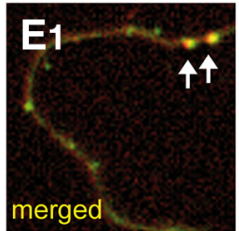

$\mathbf{F}$

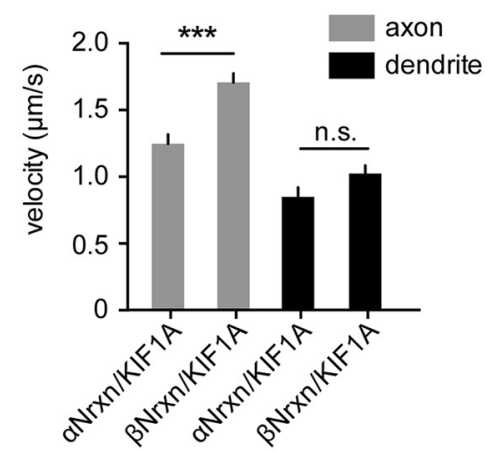

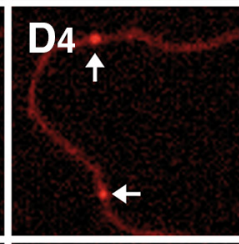

D5
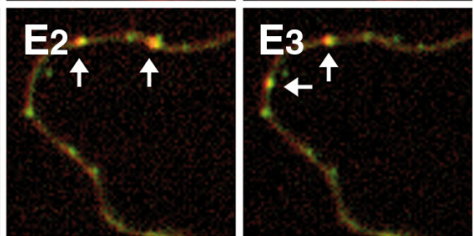

G

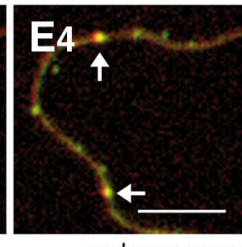

endogeneous

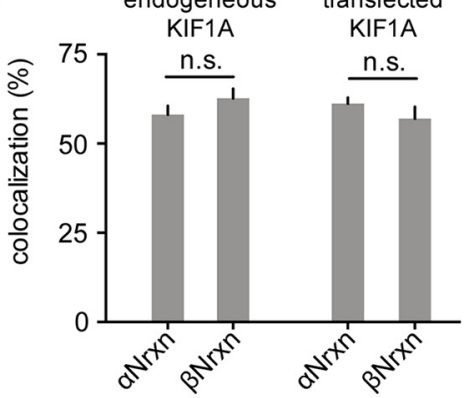

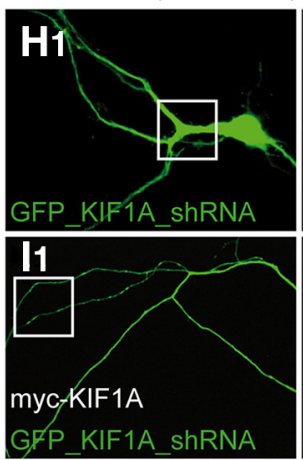
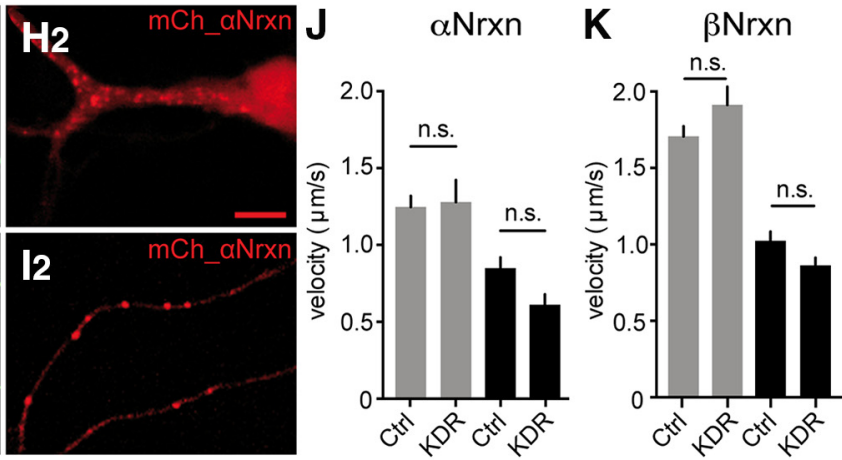

Figure 7. $\alpha$ Nrxn and $\beta$ Nrxn transport depends on the microtubule motor protein KIF1A.A,B, Average velocities of Nrxn $1 \alpha^{+}$and Nrxn1 $\beta^{+}$ STV sunder control conditions and after preincubation with DMSO (solvent control), latrunculin-A, and nocodazol to block F-actin (LatA) or microtubule (Noco) polymerization. $\mathbf{C}-\mathbf{F}$, N Nxn ${ }^{+}$STVs comigrate with transfected GFP_KIF1A at velocities similar to Nrxn/synaptophysin vesides (Fig. 6F). Scale bar, $5 \mu \mathrm{m}$. G, High degree of colocalization between $\alpha \mathrm{Nrxn}^{+}{ }^{+}$and $\beta \mathrm{Nrxn}{ }^{+}$STVs and endogenous KIF1A labeled by antibody (left bars) or transfected GFP_KIF1A (right bars). $\boldsymbol{H}$, shRNA-mediated knock-down of KIF1A (H1) leads to accumulation of $\alpha$ Nixn in soma and initial segments (H2). I-K, Expression ofshRNA-resistentmyc-KIF1A (II) is abletorescuetheknock-down and reinstatelocalization (I2) and velocities of $\alpha \mathrm{Nrxn}^{+}$(I) and $\beta \mathrm{Nrxn}^{+}(\boldsymbol{K})$ STVs. Scale bar, $20 \mu \mathrm{m}$. Data in $\boldsymbol{A}, \boldsymbol{B}, \boldsymbol{F}, \boldsymbol{G}, \boldsymbol{J}$, and $\boldsymbol{K}$ are expressed as means \pm SEM and were derived from a total of $>264$ neurons/27 transfected cultures. Statistical significance was tested by Student'st test. ${ }^{* * *} p<0.001$. 
$\beta \mathrm{Nrxn} / \mathrm{KIF} 1 \mathrm{~A}^{+}$vesicles mimicked the values for Nrxn/synaptophysin comigration, confirming the faster speed of $\beta \mathrm{Nrxn}$ STVs in axons (Fig. 7F).

To prove directly that KIF1A is the molecular motor responsible for moving Nrxns, we used a combined knock-down/rescue strategy described previously (Xue et al., 2010; Liu et al., 2012). Transfecting this shRNA against KIF1A, we knocked down the protein in our primary neurons (data not shown), causing $\mathrm{Nrxn}^{+}$STV s to accumulate in the soma and axon initial segments of neurons expressing the shRNA (Fig. 7H). To ensure that this was not an off-target effect, we rescued the knock-down phenotype with a myc-tagged KIF1A resistant to the shRNA (Fig. 7I1). Under rescue conditions (KDR), $\mathrm{Nrxn}^{+}$STVs distributed normally into neurites (Fig. 7I2) and migrated with velocities indistinguishable from control cells (Fig. $7 J, K)$. Together, these data indicate that $\mathrm{Nrxn}^{+}$STVs and $\beta \mathrm{Nrxn}{ }^{+}$ STVs use the fast-microtubule-dependent transport to move toward synapses. This leaves the question of where $\mathrm{Nrxn}^{+}$STV s are inserted into the plasma membrane and how they are delivered to synaptic terminals.

\section{Nrxns enrich at excitatory and inhibitory synapses after surface delivery}

To show that Nrxn ${ }^{+}$STV s actually fuse with the plasma membrane, we used pHluorin-tagged $\alpha$ Nrxns. We selected regions of transfected processes for FRAP, bleached large areas by short laser pulses, and monitored the spontaneous appearance of surface Nrxns by live imaging at $2-10 \mathrm{~Hz}$ for 5-20 min (Fig. 8A,B). At different time points during image sequences, we observed sharp increases of fluorescence intensity with longer decay (Fig. $8 B)$. To determine whether these events actually corresponded to fusion of $\mathrm{Nrxn}^{+}$STVs, we monitored in parallel the appearance of pHluorin_Nrxn and pHTomato_synaptophysin cotransfected into neurons (Fig. 8C). In virtually all cases recorded, the increase in Nrxn fluorescence was accompanied by an increase of synaptophysin and vice versa, overlapping precisely in location and kinetics (Fig. 8D). Because Nrxn and synaptophysin were strictly colocalized in large fusion events, we used pHTomato_synaptophysin in combination with the $\mathrm{Ca}^{2+}$ indicator dye GCaMP6f (Chen et al., 2013) to determine whether STVs reached the plasma membrane at active synaptic terminals, identified by $\mathrm{Ca}^{2+}$ influx upon stimulation (Fig. $8 E, F$ ). Interestingly, synaptophysin ${ }^{+}$STVs appeared to fuse mostly outside of active synapses because we did not see clear overlap of $\mathrm{Ca}^{2+}$ signals and STV fusion (Fig. 8G,H). It should be noted, however, that the use of pHTomato, which has a lower dynamic range than pHluorin, to detect surface synaptophysin or Nrxn likely biased this analysis toward large, full-collapse fusion events. It cannot be excluded at present that additional smaller or more transient fusion events also contribute to the surface delivery of STVs and Nrxns, possibly also within synapses. Due to the high surface mobility and only transient confinement in synaptic terminals (Fig. 2), a direct insertion of $\mathrm{Nrxn}^{+}$STVs into the active zones may not be necessary to deliver Nrxn. Therefore, we propose that a combination of intracellular transport, STV fusion events outside of synaptic terminals, and distribution via lateral diffusion, with all three steps intricately regulated, targets Nrxn to synapses.

Such a scenario raises the question of if and how strongly $\alpha$ Nrxns and $\beta$ Nrxns enrich at synapses. For this, we compared the relative amounts of $\alpha$ Nrxns, $\beta$ Nrxns, and the Nxph $1 / \alpha$ Nrxn complex at excitatory and inhibitory terminals normalized to extrasynaptic sites of transfected axons (Fig. 9A). We noticed that $\beta$ Nrxns got more enriched than $\alpha$ Nrxns at excitatory synapses and cotransfected Nxph1 caused an enrichment of its complex with $\alpha$ Nrxns that exceeded the effect of $\alpha$ Nrxns or $\beta$ Nrxns alone (Fig. 9B). In addition, we found that both Nrxns enriched threefold at inhibitory synapses and accumulation was strongest for the Nxph $1 / \alpha$ Nrxn complex (Fig. 9B). These results suggest that a lower surface mobility, as determined for the complex above (Figs. 2, 3, 4), does not limit its presence or enrichment in synapses. Therefore, in addition to securing delivery of sufficient molecules to terminals by lateral diffusion, the distinct surface mobilities inside synapses found above may also point to direct effects on synaptic function.

\section{Synaptic enrichment of Nxph1/ $\alpha$ Nrxn affects GABA $A_{A}$ s}

To study how the Nxph $1 / \alpha$ Nrxn complex, which was most distinctive in surface mobility (Fig. 2) and synaptic enrichment (Fig. 9), may exert an effect on synaptic function, we analyzed changes in postsynaptic receptor distribution. We chose the Nxph1/ $\alpha$ Nrxn complex because we showed recently that transgenic expression of Nxph1 at excitatory synapses, which normally do not contain this ligand, is able to change synaptic short-term plasticity (Born et al., 2014). Because we observed more functional $\mathrm{GABA}_{\mathrm{A}} \mathrm{R}$ at transgenic synapses in that study (Born et al., 2014), we now tested directly the ability of Nxph $1 / \alpha$ Nrxn to recruit $\mathrm{GABA}_{\mathrm{A}} \mathrm{R}$ subunits at inhibitory and excitatory terminals compared with uncomplexed $\alpha$ Nrxns (Fig. 10). To monitor the accumulation of $\mathrm{GABA}_{\mathrm{A}} \mathrm{R}$ in primary hippocampal neurons, we first labeled the surface population of these receptors in $\mathrm{VGAT}^{-}$and VGlut ${ }^{+}$synapses (Fig. 10A). The Nxph1/ $\alpha$ Nrxn complex was able to accumulate $\mathrm{GABA}_{\mathrm{A}} \mathrm{R} \gamma 2$ subunits about twofold at inhibitory synapses (Fig. 10B). Nxph $1 / \alpha$ Nrxn was more efficient in this process than $\alpha$ Nrxns alone (Fig. 10C,D), reflecting their differences in surface mobility (Fig. 2) and synaptic enrichment (Fig. 9). Consistently, Nxph $1 / \alpha$ Nrxn recruited GABA $\mathrm{A}_{\mathrm{A}} \mathrm{also}$ ectopically to excitatory terminals in primary neurons (Fig. 10B), underscoring our recent data from transgenic mice (Born et al., 2014).

Finally, we performed SPT experiments to determine whether Nxph $1 / \alpha$ Nrxn affects the diffusion dynamics of $\mathrm{GABA}_{\mathrm{A}} \mathrm{R}$, an important parameter that has been linked to synaptic plasticity (Bannai et al., 2009). Using an antibody directed against the extracellular domain of the $\gamma$-subunit of $\mathrm{GABA}_{\mathrm{A}} \mathrm{Rs}$, as in the earlier study (Bannai et al., 2009), we monitored the diffusion properties of endogenous $\mathrm{GABA}_{\mathrm{A}} \mathrm{R}$ in synapses. We compared the effect of expressing $\alpha$ Nrxns or the Nxph $1 / \alpha$ Nrxn complex on surface mobility of $\mathrm{GABA}_{\mathrm{A}} \mathrm{Rs}$ colocalizing with active synaptic terminals (Fig. 10E). Coexpression of Nxph $1 / \alpha \operatorname{Nrxn}(+\mathrm{SS} 4)$ strongly reduced the diffusion coefficient of $\mathrm{GABA}_{\mathrm{A}} \mathrm{Rs}$, whereas expression of $\alpha \operatorname{Nrxn}(+\mathrm{SS} 4)$ alone only revealed a tendency toward reduced surface mobility. Interestingly, variants without the insert in SS4, $\operatorname{Nxph} 1 / \alpha \operatorname{Nrxn}(-\mathrm{SS} 4)$ and $\alpha \operatorname{Nrxn}(-\mathrm{SS} 4)$, did not alter the surface mobility of $\mathrm{GABA}_{\mathrm{A}}$ Rs (Fig. $10 \mathrm{E}$ ), possibly reflecting preference for other interaction partners such as $\alpha$-dystroglycan (Reissner et al., 2014). Together, our results indicate that the dynamic trafficking and synaptic enrichment of Nxph $1 / \alpha$ Nrxn may have effects on $\mathrm{GABA}_{\mathrm{A}} \mathrm{R}$ and possibly other postsynaptic receptors.

\section{Discussion}

Using single-particle tracking and time-lapse imaging, we explored the dynamic trafficking of Nrxns outside and inside of synapses and during intracellular transport to the surface. We studied overexpressed, epitope-tagged Nrxn/Nxph1 molecules because no antibodies are available against endogenous proteins that would allow these experiments. Any such approach has to 

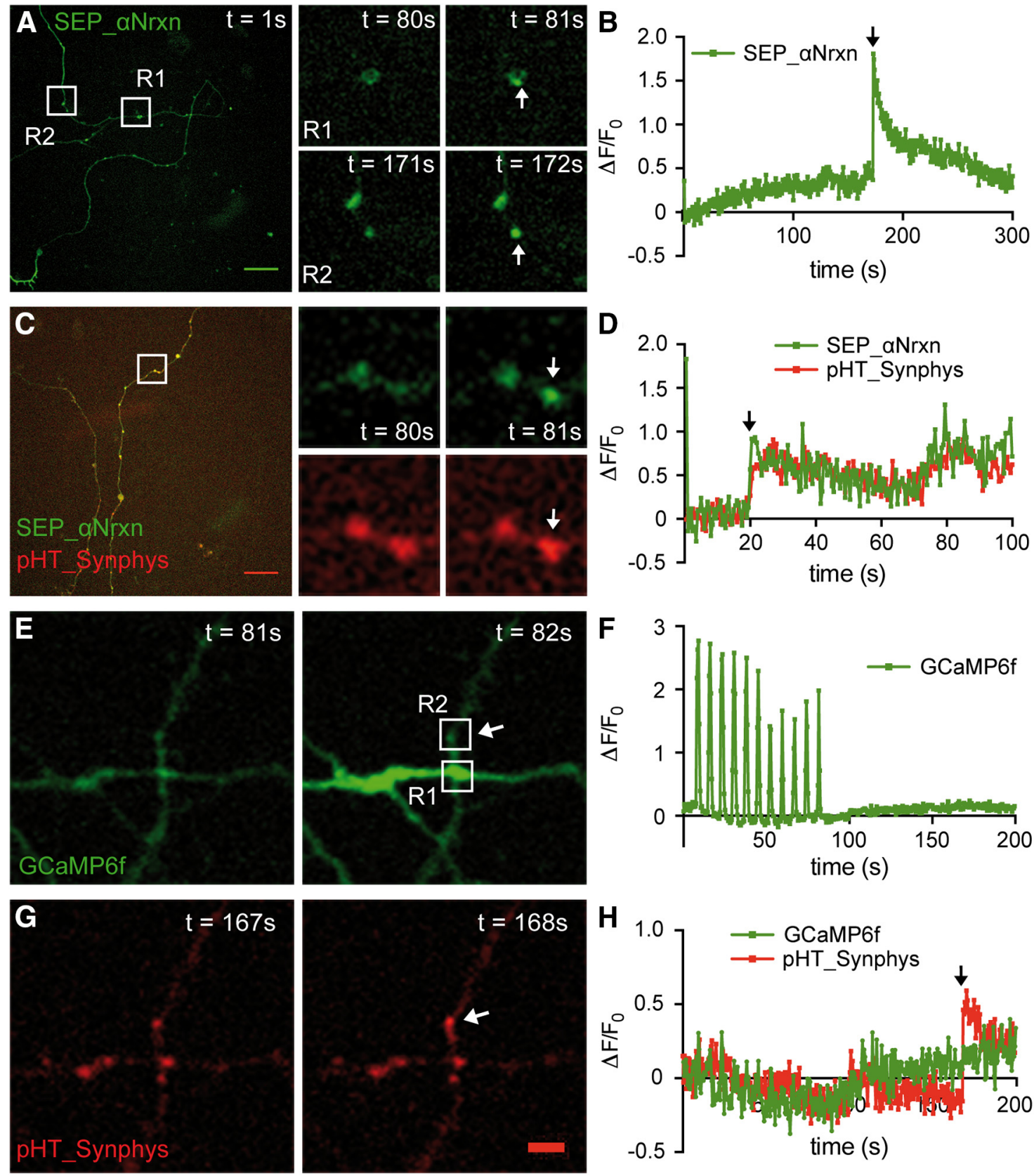

Figure 8. Synchronous surface delivery of Nrxn and synaptophysin outside of active terminals. $\boldsymbol{A}, \boldsymbol{B}$, Sample images of spontaneous plasma membrane fusion of pHluorin(SEP)_Nrxn1 $\alpha$ in two different regions (R1, R2) on an axon of transfected primary neurons. The fusion events occur at different time points after bleaching the area with a $405 \mathrm{~nm}$ laser (FRAP). Scale bar, $20 \mu \mathrm{m}$. Changes of fluorescence intensity over time were recorded at DIV14 and expressed as $\Delta F / F_{0}$ after substraction of background, facilitating recognition of fusion events $(\boldsymbol{B})$. $\boldsymbol{C}, \boldsymbol{D}$, In neurons cotransfected with pHluorin_Nrxn1 $\alpha$ and pHTomato_synaptophysin (C), both molecules appear simultaneously and with similar kinetics at the axonal surface (D), indicating fusion of $\alpha$ Nrxn/synaptophysin ${ }^{+}$STVs. $\boldsymbol{E}-\boldsymbol{H}, \mathrm{GCaMP6f} \mathrm{Ca}^{2+}$ indicator $(\boldsymbol{E})$ and pHTomato_synaptophysin $(\boldsymbol{G})$ cotransfected into primary neurons. Changes of fluorescence intensity over time reliably detect $\mathrm{Ca}^{2+}$ influx upon repetitive stimulation ( $\boldsymbol{F}$; recorded from R1). Fusion events of STVs appeared outside of active terminals and independent of stimulation/ $\mathrm{Ca}^{2+}$ influx ( $\boldsymbol{H}$; recorded from R2, arrow labels STV fusion). Scale bar, $5 \mu \mathrm{m}$.

consider that epitope tagging and/or overexpression may produce artifacts or limit the conclusions derived from those experiments. Therefore, we addressed the following, possibly confounding aspects. First, the surface mobility of Nrxns was tested with differently sized epitope tags (EGFP, Flag) and attached fluorophores (QDs, nanobodies) because larger molecular complexes may bias mobility (Fig. 1). Interestingly, we observed that all methods applied reliably revealed a highly mobile population of $\alpha$ Nrxns on axons as well as within synapses. However, nanobodies showed a slightly more homogeneous distribution of diffusion in synapses, whereas QD tracking typically revealed a second, more immobile population, which is also apparent in the analyses shown in Figure 2 (e.g., Fig. $2 E$ or $K$ ). Despite this small additional population, the QD data turned out to be robust enough to reveal clear and significant differences between Nrxn variants or between extrasynaptic regions and glutamatergic or GABAergic terminals (Figs. 2, 3, 4). Future research will have to explore whether the presence of an additional, more immobile Nrxn population was due to size limitations of QD tracking within synaptic terminals or to a bias of nanobody tracking toward higher mobilities. 

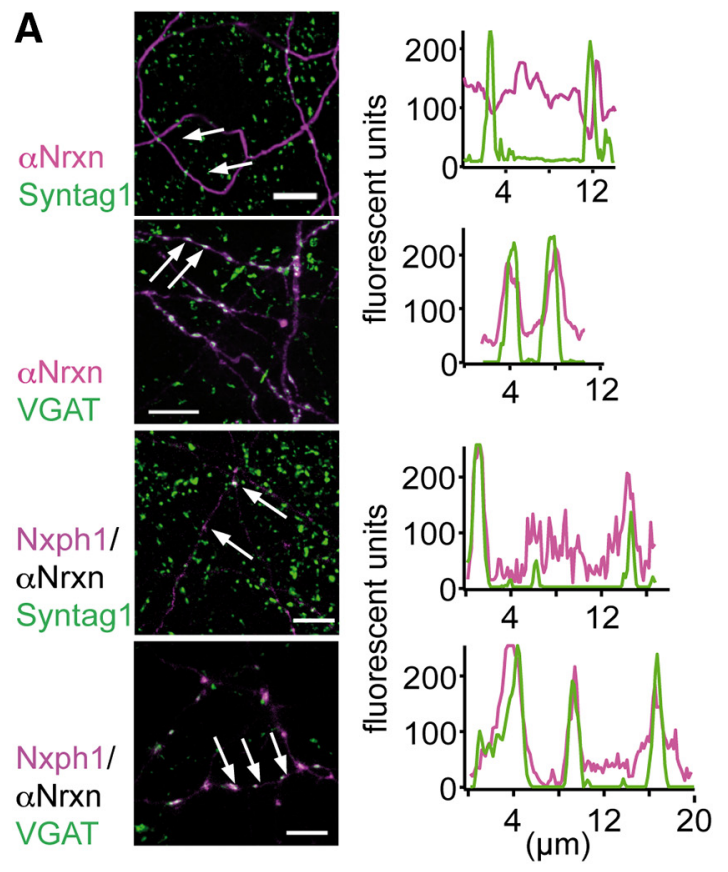

B

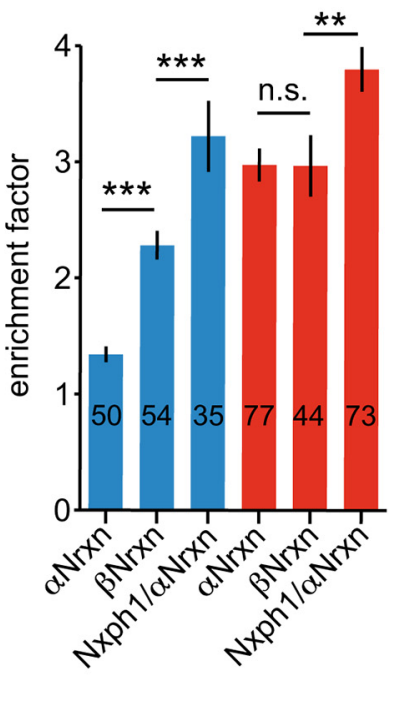

Figure 9. Enrichment of Nrxns and the Nxph1/ $\alpha$ Nrxn complex at synapses. A, Sample images of pHluorin(SEP)_Nrxn1 $\alpha^{+}$ axons of glutamatergic and GABAergic neurons. Strong accumulation of $\alpha$ Nrxns seen at VGAT/Syntag $1^{+}$putatively inhibitory terminals compared with Syntag $1^{+}$putatively excitatory synapses is supported by corresponding line scans (right panels). Scale bar, $10 \mu \mathrm{m}$. B, Enrichment of $\alpha$ Nrxns, $\beta$ Nrxns, and the Nxph1/ $\alpha$ Nrxn complex at excitatory (blue) and inhibitory (red) synapses normalized to extrasynaptic axonal sites (set to 1). Data are means \pm SEM and were collected from 3 different cultures for each construct with number of analyzed synapses indicated in bars. Statistical significance was tested by a one-way ANOVA test followed by a Keuls-Newman post test. ${ }^{* *} p<0.0001,{ }^{* *} p<0.001$.

Second, similar to the analysis of surface mobility, we used different epitopes (EGFP, mCherry, HRP) in this and a previous study to investigate the intracellular transport of Nrxns. In addition, we have previously tested different positions within the Nrxn molecules ( $\mathrm{N}$ terminus, extracellular to transmembrane region). These experiments all demonstrated that Nrxns are transported as cargo on STVs (Figs. 5, 6; Fairless et al., 2008). Moreover, the choice of EGFP or mCherry did not affect the velocity of Nrxn-positive STVs (Figs. 5, 6).

Third, to validate our data on Nrxn surface mobility with another method and to compare our data with published results, we performed a set of FRAP experiments. We found that the fraction of mobile Nrxn molecules was comparable between SPT and FRAP measurements (Fig. 1) and between cultured primary neurons (Fig. 1) and slice cultures (Fu and Huang, 2010).

Finally, we tried to determine how much the overexpression of tagged Nrxns influenced our results, arguably the most difficult variable to assess. The comparable surface mobilities derived from FRAP (Fig. 1; Fu and Huang, 2010) and SPT experiments (Fig. 2) suggest that the level and mode of overexpression (transgenic mice vs transfection) did not alter the diffusion coefficient nor the fraction of mobile molecules. In addition, we observed that the removal of endogenous $\alpha$ Nrxns reduced the diffusion rates of transfected $\alpha$ Nrxn variants in TKO neurons, but did not abolish the presence of highly mobile $\alpha$ Nrxns (Fig. 2). This result was expected if transfected Nrxns engage in normal protein-protein interactions because more ligands may be available in the TKO to interact. The reduction in the diffusion coefficient actually demonstrates that transfected, overexpressed Nrxns behave like endogenous Nrxns by taking their positions. This is supported by our finding that prevention of such interactions leads to higher mobilities (Fig. 3). For the intracellular transport of $\alpha$ Nrxns, we have previously shown that it is largely independent of endogenous protein (Fairless et al., 2008). In support, our current analysis reveals that the velocity of $\alpha \mathrm{Nrxn}^{+}$STVs is indistinguishable between WT and TKO neurons (Fig. 6). Finally, important previous studies have used overexpressed Nrxns extensively to unravel their functions, for example, in synapse formation assays that revealed the role of Nrxn in differentiating novel contacts (Graf et al., 2004; Boucard et al., 2005; Nam and Chen, 2005; Chih et al., 2006). Therefore, based on our controls and published evidence, we believe that overexpressed, epitope-tagged Nrxns are an acceptable tool to study their dynamic trafficking.

We first observed a higher surface mobility of $\alpha$ Nrxns compared with $\beta$ Nrxns (Fig. 2), which is an unexpected result in view of the much longer and rigid extracellular domains of $\alpha$ Nrxns (Chen et al., 2011; Miller et al., 2011). These results agree with a study in slice cultures from transgenic mice that proposed a higher population mobility for $\alpha$ Nrxns by FRAP (Fu and Huang, 2010). Our data are also consistent with a diffusion coefficient for $\beta$ Nrxns determined in slice cultures (Biermann et al., 2014) that was only moderately slower compared with primary neurons (Fig. 2). In addition, the value determined here for extrasynaptic $\alpha$ Nrxn on axonal membranes ( $\mathrm{D} \approx 0.07 \mu \mathrm{m}^{2} / \mathrm{s}$ ) is comparable to other neuronal adhesion molecules with long extracellular domains such as SynCAM $\left(\mathrm{D} \approx 0.05 \mu \mathrm{m}^{2} / \mathrm{s}\right)$ or $N$-cadherin $\left(\mathrm{D} \approx 0.08 \mu \mathrm{m}^{2} / \mathrm{s} ;\right.$ Heine, 2012$)$. Therefore, the faster diffusion dynamics of $\alpha$ Nrxns compared with $\beta$ Nrxns indicates that size-dependent passive mechanisms are not critical for surface mobility.

In contrast, we demonstrate that $\mathrm{Ca}^{2+}$ - and SS4-dependent interactions are regulators of Nrxn surface mobility (Figs. 2, 3). Although the list of identified binding partners is likely not complete, neuroligins, LRRTMs, and dystroglycan (Ichtchenko et al., 1995; Ichtchenko et al., 1996; Sugita et al., 2001; Reissner et al., 2008; Ko et al., 2009; Siddiqui et al., 2010; Reissner et al., 2014), and possibly also calsyntenin-3 (Pettem et al., 2013; Lu et al., 2014; Um et al., 2014), are known to require $\mathrm{Ca}^{2+}$ for their interaction. Binding affinities are further regulated by splice site SS4 because neuroligins, LRRTMs, and dystroglycan favor insertless and cerebellin insert-containing variants (Ichtchenko et al., 1995; Sugita et al., 2001; Boucard et al., 2005; Reissner et al., 2008; Ko et al., 2009; de Wit et al., 2009b; Koehnke et al., 2010; Uemura et al., 2010; Joo et al., 2011; Matsuda and Yuzaki, 2011; Lee et al., 2012; Reissner et al., 2014). The fact that known splice-variantdependent binding properties of Nrxns are reflected by differences in mobility (Fig. 3) underscores the importance of alternative splicing and transcriptional regulation (Chih et al., 2006; Iijima et al., 2011; Aoto et al., 2013; Ehrmann et al., 2013; Runkel et al., 2013; Treutlein et al., 2014).

We also reveal that the surface mobility of $\alpha$ Nrxns is modulated by complex formation with Nxph1 (Missler et al., 1998). In contrast to $\alpha$ Nrxns (Ullrich et al., 1995), Nxphs are only ex- 
pressed by subpopulations of neurons (Petrenko et al., 1996; Beglopoulos et al., 2005). Our observation that efficient surface targeting of Nxph1 requires coexpression with $\alpha$ Nrxna (Fig. 4), but not vice versa, constitutes an asymmetric dependence. This asymmetry unveils a surprising twist because initial sequence analysis, which identified a signal peptide, preprodomain, and a bibasic proteolytic cleavage site, suggested independently secreted Nxph (Petrenko et al., 1996; Missler and Südhof, 1998; Missler et al., 1998). Recent data from transgenic overexpression of Nxph1 showed alterations of synaptic function and ectopic accumulation of functional $\mathrm{GABA}_{\mathrm{A}} \mathrm{R}$ subunits (Born et al., 2014). Given the asymmetric dependence on $\alpha$ Nrxns (Fig. 4), the transgenic Nxph1 phenotype might be based on the slow diffusion and longer dwell time of Nxph $1 / \alpha$ Nrxn complexes (Fig. 2). Accordingly, biochemical data showed that complex formation between the LNS2 domain of $\alpha$ Nrxn with Nxph1 is mutually exclusive with $\alpha$-dystroglycan, and thus favors association with particular Nlgn variants at the LNS6 domain (Reissner et al., 2014). This in turn may decrease the surface mobility (Figs. 2, 3).

Enrichment of Nxph $1 / \alpha$ Nrxn at terminals led to recruitment and stabilization of endogenous $\mathrm{GABA}_{\mathrm{A}} \mathrm{R}$ subunits in transfected synapses (Figs. 9, 10), consistent with Nxph1 overexpression in transgenic mice (Born et al., 2014). The stronger effect found in presence of Nxph $1 / \alpha$ Nrxn compared with $\alpha$ Nrxns and at inhibitory compared with excitatory synapses (Fig. 10), mirrors the difference in their surface mobilities (Fig. 2 ). In agreement, $\alpha$ Nrxns expressed in heterologous cells induced clustering of $\mathrm{GABA}_{\mathrm{A}} \mathrm{R}$ subunits in contacting dendrites (Graf et al., 2004; Kang et al., 2008) and inhibitory synapses were reduced in TKO (Dudanova et al., 2007). In addition, Nrxns were linked to postsynaptic $\mathrm{GABA}_{\mathrm{A}} \mathrm{R}$ function in lentivirus-mediated knock-down experiments in primary neurons (Zhang et al., 2010). Therefore, the recruitment of $\mathrm{GABA}_{\mathrm{A}} \mathrm{R}$ and the down-regulation of its diffusion dynamics by Nxph $1 / \alpha$ Nrxn demonstrates that the complex can shape synaptic function.

Although the diffusion coefficient of Nrxns is considerably high, diffusion is only effective at short distances (Rusakov et al., 2011), for example, within synaptic terminals or their immediate vicinity. We therefore hypothesized that neurons rely on fast intracellular transport of Nrxns and discovered that they are transported as cargo via typical STVs (Figs. 5, 6, 7). Unlike surface mobility, $\beta \mathrm{Nrxn}^{+}$STVs moved faster than $\alpha \mathrm{Nrxn}^{+}$STVs within axons (Fig. 6), possibly because smaller
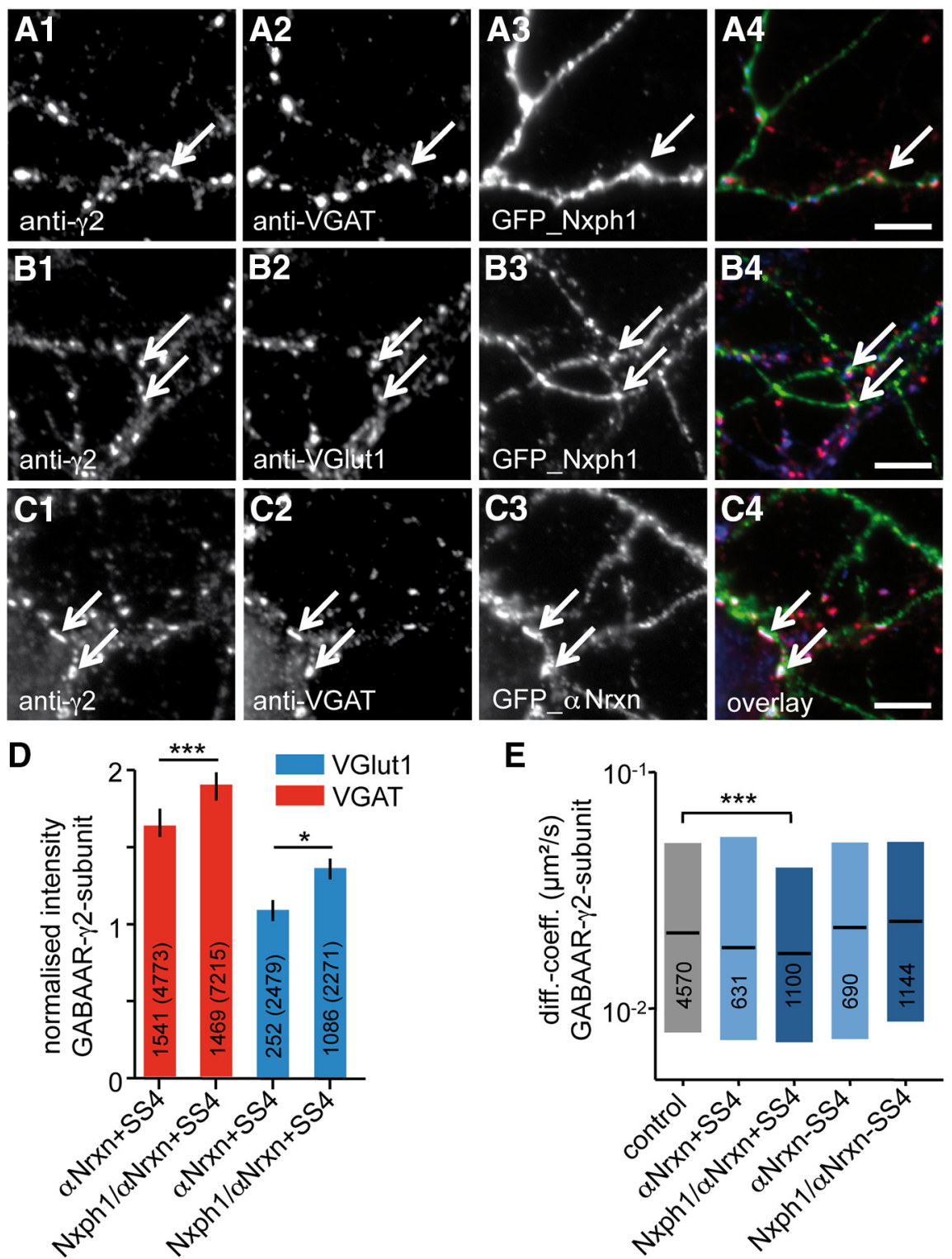

Figure 10. $\alpha$ Nrxns and the Nxph1/ $\alpha$ Nrxn complex are effective in recruiting GABA ${ }_{A}$ R subunits to synapses. $\boldsymbol{A}-\boldsymbol{C}$, Primary hippocampal neurons transfected with the pHluorin(SEP)_Nxph1/ $\alpha$ Nrxn complex or SEP_ $\alpha$ Nrxns alone are colabeled against $\mathrm{GABA}_{A} R \gamma 2$, and VGAT or VGlut1 to distinguish inhibitory from excitatory terminals. Scale bar, $10 \mu \mathrm{m}$. D, $\alpha$ Nrxns and the Nxph1/ $\alpha$ Nrxn complex cause enrichment of $\mathrm{GABA}_{A} \mathrm{R} \gamma 2$ subunits at inhibitory synapses (red) and Nxph1/ $\alpha$ Nrxn also at excitatory synapses (blue). Data are shown as means \pm SEM, with the number of analyzed transfected and nontransfected (in paranthesis) synapses shown in bars. Statistical significance was tested by one-way ANOVA variance test followed by Newman-Keuls test. ${ }^{*} p<0.05,{ }^{* * *} p<0.0001$. $\boldsymbol{E}$, SPT with QD-labeled antibodies against endogenous $\mathrm{GABA}_{\mathrm{A}} \mathrm{R} \gamma 2$ on axons of neurons transfected with $\alpha$ Nrxns or the Nxph1/ $\alpha$ Nrxn complex ( \pm insert at SS4). Coexpression of Nxph1 decreases diffusion coefficients of $G_{A B A} R \gamma$ when the insert is present in $\alpha$ Nrxn (+SS4). Data are shown as median plus IQR (25-75\%) and were collected from 3 independent cultures. Significance was tested by a Kruskal-Wallis test followed by a Dunn's test. ${ }^{* * *} p<0.0001$.

$\beta$ Nrxns can assemble more densely in sheet-like superstructures (Tanaka et al., 2012), providing more access for their molecular motor KIF1A (Fig. 7). Velocities of 1-2 $\mu \mathrm{m} / \mathrm{s}$ appear sufficient to deliver $\mathrm{Nrxn}^{+}$STVs even to distant terminals, in particular because increased neuronal activity could augment speed (Fig. 6). Therefore, the combination of fast intracellular transport via STVs, fusion near active synapses (Fig. 8), and lateral diffusion on the surface appears ideally suited to maintain and modulate the amount of Nrxn variants at synapses. Future work will have to address how their dynamic trafficking affects synaptic function. 


\section{References}

Ahmari SE, Buchanan J, Smith SJ (2000) Becausesembly of presynaptic active zones from cytoplasmic transport packets. Nat Neurosci 3:445-451. CrossRef Medline

Anggono V, Huganir RL (2012) Regulation of AMPA receptor trafficking and synaptic plasticity. Curr Opin Neurobiol 22:461-469. CrossRef Medline

Aoto J, Martinelli DC, Malenka RC, Tabuchi K, Südhof TC (2013) Presynaptic neurexin-3 alternative splicing trans-synaptically controls postsynaptic AMPA receptor trafficking. Cell 154:75-88. CrossRef Medline

Bannai H, Lévi S, Schweizer C, Inoue T, Launey T, Racine V, Sibarita JB, Mikoshiba K, Triller A (2009) Activity-dependent tuning of inhibitory neurotransmission based on GABAAR diffusion dynamics. Neuron 62: 670-682. CrossRef Medline

Beglopoulos V, Montag-Sallaz M, Rohlmann A, Piechotta K, Ahmad M, Montag D, Missler M (2005) Neurexophilin 3 is highly localized in cortical and cerebellar regions and is functionally important for sensorimotor gating and motor coordination. Mol Cell Biol 25:7278-7288. CrossRef Medline

Biermann B, Ivankova-Susankova K, Bradaia A, Abdel Aziz S, Besseyrias V, Kapfhammer JP, Missler M, Gassmann M, Bettler B (2010) The Sushi domains of GABAB receptors function as axonal targeting signals. J Neurosci 30:1385-1394. CrossRef Medline

Biermann B, Sokoll S, Klueva J, Missler M, Wiegert JS, Sibarita JB, Heine M (2014) Imaging of molecular surface dynamics in brain slices using single-particle tracking. Nat Commun 5:3024. Medline

Born G, Breuer D, Wang S, Rohlmann A, Coulon P, Vakili P, Reissner C, Kiefer F, Heine M, Pape HC, Missler M (2014) Modulation of synaptic function through the alpha-neurexin-specific ligand neurexophilin-1. Proc Natl Acad Sci U S A 111:E1274-1283. CrossRef Medline

Born G, Grayton HM, Langhorst H, Dudanova I, Rohlmann A, Woodward BW, Collier DA, Fernandes C, Missler M (2015) Genetic targeting of NRXN2 in mice unveils role in excitatory cortical synapse function and social behaviors. Front Synaptic Neurosci 7:3. Medline

Bottos A, Rissone A, Bussolino F, Arese M (2011) Neurexins and neuroligins: synapses look out of the nervous system. Cell Mol Life Sci 68:26552666. CrossRef Medline

Boucard AA, Chubykin AA, Comoletti D, Taylor P, Südhof TC (2005) A splice code for trans-synaptic cell adhesion mediated by binding of neuroligin 1 to alpha- and beta-neurexins. Neuron 48:229-236. CrossRef Medline

Boucard AA, Ko J, Südhof TC (2012) High affinity neurexin binding to cell adhesion G-protein-coupled receptor CIRL1/latrophilin-1 produces an intercellular adhesion complex. J Biol Chem 287:9399-9413. CrossRef Medline

Budreck EC, Kwon OB, Jung JH, Baudouin S, Thommen A, Kim HS, Fukazawa Y, Harada H, Tabuchi K, Shigemoto R, Scheiffele P, Kim JH (2013) Neuroligin-1 controls synaptic abundance of NMDA-type glutamate receptors through extracellular coupling. Proc Natl Acad Sci U S A 110: 725-730. CrossRef Medline

Bury LA, Sabo SL (2011) Coordinated trafficking of synaptic vesicle and active zone proteins prior to synapse formation. Neural Dev 6:24. CrossRef Medline

Chang JC, Tomlinson ID, Warnement MR, Ustione A, Carneiro AM, Piston DW, Blakely RD, Rosenthal SJ (2012) Single molecule analysis of serotonin transporter regulation using antagonist-conjugated quantum dots reveals restricted, p38 MAPK-dependent mobilization underlying uptake activation. J Neurosci 32:8919-8929. CrossRef Medline

Chen F, Venugopal V, Murray B, Rudenko G (2011) The structure of neurexin lalpha reveals features promoting a role as synaptic organizer. Structure 19:779-789. CrossRef Medline

Chen JL, Villa KL, Cha JW, So PT, Kubota Y, Nedivi E (2012) Clustered dynamics of inhibitory synapses and dendritic spines in the adult neocortex. Neuron 74:361-373. CrossRef Medline

Chen TW, Wardill TJ, Sun Y, Pulver SR, Renninger SL, Baohan A, Schreiter ER, Kerr RA, Orger MB, Jayaraman V, Looger LL, Svoboda K, Kim DS (2013) Ultrasensitive fluorescent proteins for imaging neuronal activity. Nature 499:295-300. CrossRef Medline

Chia PH, Li P, Shen K (2013) Cell biology in neuroscience: cellular and molecular mechanisms underlying presynapse formation. J Cell Biol 203: 11-22. CrossRef Medline

Chih B, Gollan L, Scheiffele P (2006) Alternative splicing controls selective trans-synaptic interactions of the neuroligin-neurexin complex. Neuron 51:171-178. CrossRef Medline

Cijsouw T, Weber JP, Broeke JH, Broek JA, Schut D, Kroon T, Saarloos I, Verhage M, Toonen RF (2014) Munc18-1 redistributes in nerve terminals in an activity- and PKC-dependent manner. J Cell Biol 204:759-775. CrossRef Medline

Dean C, Scholl FG, Choih J, DeMaria S, Berger J, Isacoff E, Scheiffele P (2003) Neurexin mediates the assembly of presynaptic terminals. Nat Neurosci 6:708-716. CrossRef Medline

de Wit J, Toonen RF, Verhaagen J, Verhage M (2006) Vesicular trafficking of semaphorin $3 \mathrm{~A}$ is activity-dependent and differs between axons and dendrites. Traffic 7:1060-1077. CrossRef Medline

de Wit J, Toonen RF, Verhage M (2009a) Matrix-dependent local retention of secretory vesicle cargo in cortical neurons. J Neurosci 29:23-37. CrossRef Medline

de Wit J, Sylwestrak E, O'Sullivan ML, Otto S, Tiglio K, Savas JN, Yates JR 3rd, Comoletti D, Taylor P, Ghosh A (2009b) LRRTM2 interacts with Neurexin 1 and regulates excitatory synapse formation. Neuron 64:799-806. CrossRef Medline

Di Biase V, Tuluc P, Campiglio M, Obermair GJ, Heine M, Flucher BE (2011) Surface traffic of dendritic CaV1.2 calcium channels in hippocampal neurons. J Neurosci 31:13682-13694. CrossRef Medline

Dobie FA, Craig AM (2011) Inhibitory synapse dynamics: coordinated presynaptic and postsynaptic mobility and the major contribution of recycled vesicles to new synapse formation. J Neurosci 31:10481-10493. CrossRef Medline

Dolphin AC (2012) Calcium channel auxiliary alpha2delta and beta subunits: trafficking and one step beyond. Nat Rev Neurosci 13:542-555. Medline

Dudanova I, Tabuchi K, Rohlmann A, Südhof TC, Missler M (2007) Deletion of alpha-neurexins does not cause a major impairment of axonal pathfinding or synapse formation. J Comp Neurol 502:261-274. CrossRef Medline

Dupuis JP, Ladépêche L, Seth H, Bard L, Varela J, Mikasova L, Bouchet D, Rogemond V, Honnorat J, Hanse E, Groc L (2014) Surface dynamics of GluN2B-NMDA receptors controls plasticity of maturing glutamate synapses. EMBO J 33:842-861. CrossRef Medline

Ehrmann I, Dalgliesh C, Liu Y, Danilenko M, Crosier M, Overman L, Arthur HM, Lindsay S, Clowry GJ, Venables JP, Fort P, Elliott DJ (2013) The tissue-specific RNA binding protein T-STAR controls regional splicing patterns of neurexin pre-mRNBecause in the brain. PLoS Genet 9:e1003474. CrossRef Medline

Ermolyuk YS, Alder FG, Henneberger C, Rusakov DA, Kullmann DM, Volynski KE (2012) Independent regulation of basal neurotransmitter release efficacy by variable $\mathrm{Ca}(2)+$ influx and bouton size at small central synapses. PLoS Biol 10:e1001396. CrossRef Medline

Etherton MR, Blaiss CA, Powell CM, Südhof TC (2009) Mouse neurexin1alpha deletion causes correlated electrophysiological and behavioral changes consistent with cognitive impairments. Proc Natl Acad Sci U S A 106:17998-18003. CrossRef Medline

Fairless R, Masius H, Rohlmann A, Heupel K, Ahmad M, Reissner C, Dresbach T, Missler M (2008) Polarized targeting of neurexins to synapses is regulated by their C-terminal sequences. J Neurosci 28:12969 12981. CrossRef Medline

Fu Y, Huang ZJ (2010) Differential dynamics and activity-dependent regulation of alpha- and beta-neurexins at developing GABAergic synapses. Proc Natl Acad Sci U S A 107:22699-22704. CrossRef Medline

Giannone G, Mondin M, Grillo-Bosch D, Tessier B, Saint-Michel E, Czöndör K, Sainlos M, Choquet D, Thoumine O (2013) Neurexin-1beta binding to neuroligin-1 triggers the preferential recruitment of PSD-95 versus gephyrin through tyrosine phosphorylation of neuroligin-1. Cell Rep 3:1996-2007. CrossRef Medline

Gokce O, Südhof TC (2013) Membrane-tethered monomeric neurexin LNS-domain triggers synapse formation. J Neurosci 33:14617-14628. CrossRef Medline

Graf ER, Zhang X, Jin SX, Linhoff MW, Craig AM (2004) Neurexins induce differentiation of GABA and glutamate postsynaptic specializations via neuroligins. Cell 119:1013-1026. CrossRef Medline

Groc L, Lafourcade M, Heine M, Renner M, Racine V, Sibarita JB, Lounis B, Choquet D, Cognet L (2007) Surface trafficking of neurotransmitter receptor: comparison between single-molecule/quantum dot strategies. J Neurosci 27:12433-12437. CrossRef Medline 
Heine M (2012) Surface traffic in synaptic membranes. Adv Exp Med Biol 970:197-219. CrossRef Medline

Heine M, Thoumine O, Mondin M, Tessier B, Giannone G, Choquet D (2008a) Activity-independent and subunit-specific recruitment of functional AMPA receptors at neurexin/neuroligin contacts. Proc Natl Acad Sci U S A 105:20947-20952. CrossRef Medline

Heine M, Groc L, Frischknecht R, Béique JC, Lounis B, Rumbaugh G, Huganir RL, Cognet L, Choquet D (2008b) Surface mobility of postsynaptic AMPARs tunes synaptic transmission. Science 320:201-205. CrossRef Medline

Hirokawa N, Noda Y, Tanaka Y, Niwa S (2009) Kinesin superfamily motor proteins and intracellular transport. Nat Rev Mol Cell Biol 10:682-696. Medline

Ichtchenko K, Hata Y, Nguyen T, Ullrich B, Missler M, Moomaw C, Südhof TC (1995) Neuroligin 1: a splice site-specific ligand for beta-neurexins. Cell 81:435-443. CrossRef Medline

Ichtchenko K, Nguyen T, Südhof TC (1996) Structures, alternative splicing, and neurexin binding of multiple neuroligins. J Biol Chem 271:26762682. CrossRef Medline

Iijima T, Wu K, Witte H, Hanno-Iijima Y, Glatter T, Richard S, Scheiffele P (2011) SAM68 regulates neuronal activity-dependent alternative splicing of neurexin-1. Cell 147:1601-1614. CrossRef Medline

Joo JY, Lee SJ, Uemura T, Yoshida T, Yasumura M, Watanabe M, Mishina M (2011) Differential interactions of cerebellin precursor protein (Cbln) subtypes and neurexin variants for synapse formation of cortical neurons. Biochem Biophys Res Commun 406:627-632. CrossRef Medline

Kaech S, Banker G (2006) Culturing hippocampal neurons. Nat Protoc 1:2406-2415. CrossRef Medline

Kang Y, Zhang X, Dobie F, Wu H, Craig AM (2008) Induction of GABAergic postsynaptic differentiation by alpha-neurexins. J Biol Chem 283: 2323-2334. CrossRef Medline

Kattenstroth G, Tantalaki E, Südhof TC, Gottmann K, Missler M (2004) Postsynaptic N-methyl-D-aspartate receptor function requires alphaneurexins. Proc Natl Acad Sci U S A 101:2607-2612. CrossRef Medline

Kechkar A, Nair D, Heilemann M, Choquet D, Sibarita JB (2013) Real-time analysis and visualization for single-molecule based super-resolution microscopy. PLoS One 8:e62918. CrossRef Medline

Ko J, Fuccillo MV, Malenka RC, Südhof TC (2009) LRRTM2 functions as a neurexin ligand in promoting excitatory synapse formation. Neuron 64: 791-798. CrossRef Medline

Koehnke J, Katsamba PS, Ahlsen G, Bahna F, Vendome J, Honig B, Shapiro L, Jin X (2010) Splice form dependence of beta-neurexin/neuroligin binding interactions. Neuron 67:61-74. CrossRef Medline

Kraszewski K, Mundigl O, Daniell L, Verderio C, Matteoli M, De Camilli P (1995) Synaptic vesicle dynamics in living cultured hippocampal neurons visualized with CY3-conjugated antibodies directed against the lumenal domain of synaptotagmin. J Neurosci 15:4328-4342. Medline

Kwon HB, Sabatini BL (2011) Glutamate induces de novo growth of functional spines in developing cortex. Nature 474:100-104. CrossRef Medline

Lau CG, Zukin RS (2007) NMDA receptor trafficking in synaptic plasticity and neuropsychiatric disorders. Nat Rev Neurosci 8:413-426. Medline

Lee JR, Shin H, Ko J, Choi J, Lee H, Kim E (2003) Characterization of the movement of the kinesin motor KIF1A in living cultured neurons. J Biol Chem 278:2624-2629. CrossRef Medline

Lee SJ, Uemura T, Yoshida T, Mishina M (2012) GluRdelta2 assembles four neurexins into trans-synaptic triad to trigger synapse formation. J Neurosci 32:4688-4701. CrossRef Medline

Liu JS, Schubert CR, Fu X, Fourniol FJ, Jaiswal JK, Houdusse A, Stultz CM, Moores CA, Walsh CA (2012) Molecular basis for specific regulation of neuronal kinesin-3 motors by doublecortin family proteins. Mol Cell 47:707-721. CrossRef Medline

Lu Z, Wang Y, Chen F, Tong H, Reddy MV, Luo L, Seshadrinathan S, Zhang L, Holthauzen LM, Craig AM, Ren G, Rudenko G (2014) Calsyntenin-3 molecular architecture and interaction with neurexin lalpha. J Biol Chem 289:34530-34542. CrossRef Medline

Martens H, Weston MC, Boulland JL, Gronborg M, Grosche J, Kacza J, Hoffmann A, Matteoli M, Takamori S, Harkany T, Chaudhry FA, Rosenmund C, Erck C, Jahn R, Härtig W (2008) Unique luminal localization of VGAT-C terminus allows for selective labeling of active cortical GABAergic synapses. J Neurosci 28:13125-13131. CrossRef Medline

Matsuda K, Yuzaki M (2011) Cbln family proteins promote synapse forma- tion by regulating distinct neurexin signaling pathways in various brain regions. Eur J Neurosci 33:1447-1461. CrossRef Medline

McAllister AK (2007) Dynamic aspects of CNS synapse formation. Annu Rev Neurosci 30:425-450. CrossRef Medline

Miller MT, Mileni M, Comoletti D, Stevens RC, Harel M, Taylor P (2011) The crystal structure of the alpha-neurexin-1 extracellular region reveals a hinge point for mediating synaptic adhesion and function. Structure 19: 767-778. CrossRef Medline

Missler M, Südhof TC (1998) Neurexophilins form a conserved family of neuropeptide-like glycoproteins. J Neurosci 18:3630-3638. Medline

Missler M, Hammer RE, Südhof TC (1998) Neurexophilin binding to alpha-neurexins. A single LNS domain functions as an independently folding ligand-binding unit. J Biol Chem 273:34716-34723. CrossRef Medline

Missler M, Zhang W, Rohlmann A, Kattenstroth G, Hammer RE, Gottmann K, Südhof TC (2003) Alpha-neurexins couple Ca2 + channels to synaptic vesicle exocytosis. Nature 423:939-948. CrossRef Medline

Missler M, Südhof TC, Biederer T (2012) Synaptic cell adhesion. Cold Spring Harb Perspect Biol 4:a005694. Medline

Mondin M, Labrousse V, Hosy E, Heine M, Tessier B, Levet F, Poujol C, Blanchet C, Choquet D, Thoumine O (2011) Neurexin-neuroligin adhesions capture surface-diffusing AMPA receptors through PSD-95 scaffolds. J Neurosci 31:13500-13515. CrossRef Medline

Muyldermans S (2013) Nanobodies: natural single-domain antibodies. Annu Rev Biochem 82:775-797. CrossRef Medline

Nam CI, Chen L (2005) Postsynaptic assembly induced by neurexinneuroligin interaction and neurotransmitter. Proc Natl Acad Sci U S A 102:6137-6142. CrossRef Medline

Park JJ, Gondré-Lewis MC, Eiden LE, Loh YP (2011) A distinct trans-Golgi network subcompartment for sorting of synaptic and granule proteins in neurons and neuroendocrine cells. J Cell Sci 124:735-744. CrossRef Medline

Petrenko AG, Ullrich B, Missler M, Krasnoperov V, Rosahl TW, Südhof TC (1996) Structure and evolution of neurexophilin. J Neurosci 16:43604369. Medline

Pettem KL, Yokomaku D, Luo L, Linhoff MW, Prasad T, Connor SA, Siddiqui TJ, Kawabe H, Chen F, Zhang L, Rudenko G, Wang YT, Brose N, Craig AM (2013) The specific alpha-neurexin interactor calsyntenin-3 promotes excitatory and inhibitory synapse development. Neuron 80:113128. CrossRef Medline

Reissner C, Klose M, Fairless R, Missler M (2008) Mutational analysis of the neurexin/neuroligin complex reveals essential and regulatory components. Proc Natl Acad Sci U S A 105:15124-15129. CrossRef Medline

Reissner C, Runkel F, Missler M (2013) Neurexins. Genome Biol 14:213. CrossRef Medline

Reissner C, Stahn J, Breuer D, Klose M, Pohlentz G, Mormann M, Missler M (2014) Dystroglycan binding to alpha-neurexin competes with neurexophilin-1 and neuroligin in the brain. J Biol Chem 289:27585-27603. CrossRef Medline

Ribrault C, Reingruber J, Petković M, Galli T, Ziv NE, Holcman D, Triller A (2011) Syntaxin1A lateral diffusion reveals transient and local SNARE interactions. J Neurosci 31:17590-17602. CrossRef Medline

Rozov A, Burnashev N, Sakmann B, Neher E (2001) Transmitter release modulation by intracellular $\mathrm{Ca} 2+$ buffers in facilitating and depressing nerve terminals of pyramidal cells in layer $2 / 3$ of the rat neocortex indicates a target cell-specific difference in presynaptic calcium dynamics. J Physiol 531:807-826. CrossRef Medline

Runkel F, Rohlmann A, Reissner C, Brand SM, Missler M (2013) Promoterlike sequences regulating transcriptional activity in neurexin and neuroligin genes. J Neurochem 127:36-47. Medline

Rusakov DA, Savtchenko LP, Zheng K, Henley JM (2011) Shaping the synaptic signal: molecular mobility inside and outside the cleft. Trends Neurosci 34:359-369. CrossRef Medline

Sabo SL, Gomes RA, McAllister AK (2006) Formation of presynaptic terminals at predefined sites along axons. J Neurosci 26:10813-10825. CrossRef Medline

Saxton MJ (1995) Single-particle tracking: effects of corrals. Biophys J 69: 389-398. CrossRef Medline

Schneider R, Hosy E, Kohl J, Klueva J, Choquet D, Thomas U, Voigt A, Heine M (2015) Mobility of calcium channels in the presynaptic membrane. Neuron 86:672-679. CrossRef Medline

Schreiner D, Nguyen TM, Russo G, Heber S, Patrignani A, Ahrné E, Scheiffele $\mathrm{P}$ (2014) Targeted combinatorial alternative splicing generates brain 
region-specific repertoires of neurexins. Neuron 84:386-398. CrossRef Medline

Schreiner D, Simicevic J, Ahrne E, Schmidt A, Scheiffele P (2015) Quantitative isoform-profiling of highly diversified recognition molecules. eLife 4 .

Sergé A, Fourgeaud L, Hemar A, Choquet D (2002) Receptor activation and homer differentially control the lateral mobility of metabotropic glutamate receptor 5 in the neuronal membrane. J Neurosci 22:3910-3920. Medline

Shen K, Scheiffele P (2010) Genetics and cell biology of building specific synaptic connectivity. Annu Rev Neurosci 33:473-507. CrossRef Medline

Siddiqui TJ, Pancaroglu R, Kang Y, Rooyakkers A, Craig AM (2010) LRRTMs and neuroligins bind neurexins with a differential code to cooperate in glutamate synapse development. J Neurosci 30:7495-7506. CrossRef Medline

Sugita S, Saito F, Tang J, Satz J, Campbell K, Südhof TC (2001) A stoichiometric complex of neurexins and dystroglycan in brain. J Cell Biol 154: 435-445. CrossRef Medline

Tanaka H, Miyazaki N, Matoba K, Nogi T, Iwasaki K, Takagi J (2012) Higher-order architecture of cell adhesion mediated by polymorphic synaptic adhesion molecules neurexin and neuroligin. Cell Rep 2:101-110. CrossRef Medline

Taniguchi H, Gollan L, Scholl FG, Mahadomrongkul V, Dobler E, Limthong N, Peck M, Aoki C, Scheiffele P (2007) Silencing of neuroligin function by postsynaptic neurexins. J Neurosci 27:2815-2824. CrossRef Medline

Treutlein B, Gokce O, Quake SR, Südhof TC (2014) Cartography of neurexin alternative splicing mapped by single-molecule long-read mRNA sequencing. Proc Natl Acad Sci U S A 111:E1291-1299. CrossRef Medline

Triller A, Choquet D (2008) New concepts in synaptic biology derived from single-molecule imaging. Neuron 59:359-374. CrossRef Medline

Uemura T, Lee SJ, Yasumura M, Takeuchi T, Yoshida T, Ra M, Taguchi R, Sakimura K, Mishina M (2010) Trans-synaptic interaction of GluRdelta2 and Neurexin through Cbln1 mediates synapse formation in the cerebellum. Cell 141:1068-1079. CrossRef Medline

Ullrich B, Ushkaryov YA, Südhof TC (1995) Cartography of neurexins: more than 1000 isoforms generated by alternative splicing and expressed in distinct subsets of neurons. Neuron 14:497-507. CrossRef Medline

Um JW, Pramanik G, Ko JS, Song MY, Lee D, Kim H, Park KS, Südhof TC, Tabuchi K, Ko J (2014) Calsyntenins function as synaptogenic adhesion molecules in concert with neurexins. Cell reports 6:1096-1109. CrossRef Medline

Vallee RB, Bloom GS (1991) Mechanisms of fast and slow axonal transport. Annu Rev Neurosci 14:59-92. CrossRef Medline

van de Bospoort R, Farina M, Schmitz SK, de Jong A, de Wit H, Verhage M, Toonen RF (2012) Munc13 controls the location and efficiency of dense-core vesicle release in neurons. J Cell Biol 199:883-891. CrossRef Medline

Vithlani M, Terunuma M, Moss SJ (2011) The dynamic modulation of GABA(A) receptor trafficking and its role in regulating the plasticity of inhibitory synapses. Physiol Rev 91:1009-1022. CrossRef Medline

Wittenmayer N, Körber C, Liu H, Kremer T, Varoqueaux F, Chapman ER, Brose N, Kuner T, Dresbach T (2009) Postsynaptic Neuroligin1 regulates presynaptic maturation. Proc Natl Acad Sci U S A 106:13564-13569. CrossRef Medline

Xue X, Jaulin F, Espenel C, Kreitzer G (2010) PH-domain-dependent selective transport of $\mathrm{p} 75$ by kinesin- 3 family motors in non-polarized MDCK cells. J Cell Sci 123:1732-1741. CrossRef Medline

Zhai RG, Vardinon-Friedman H, Cases-Langhoff C, Becker B, Gundelfinger ED, Ziv NE, Garner CC (2001) Becausesembling the presynaptic active zone: a characterization of an active one precursor vesicle. Neuron 29: 131-143. CrossRef Medline

Zhang C, Atasoy D, Araç D, Yang X, Fucillo MV, Robison AJ, Ko J, Brunger AT, Südhof TC (2010) Neurexins physically and functionally interact with GABA(A) receptors. Neuron 66:403-416. CrossRef Medline

Zhang W, Rohlmann A, Sargsyan V, Aramuni G, Hammer RE, Südhof TC, Missler M (2005) Extracellular domains of alpha-neurexins participate in regulating synaptic transmission by selectively affecting $\mathrm{N}-$ and $\mathrm{P} / \mathrm{Q}-$ type Ca2 + channels. J Neurosci 25:4330-4342. CrossRef Medline 